\title{
تضمين مهارات القرن الحادي والعشرين في كتب الفيزياء للمرحلة الأساسية العليا في الأردن: دراسة تحليلية
}

\author{
* وصال العمري
}

\section{Doi: //10.47015/16.4.4}

2019/10/31 تاريخ قبوله

2019/6/16 تاريخ تسلم البحث

Embedding the $21^{\text {st }}$ Century Skills in Physics Textbooks for the Higher Basic Stage in Jordan: An Analytical Study

Wesal Al-Omari, Yarmouk University, Jordan.

Abstract: The present study aimed at investigating the extent of embedding of the twenty-first century skills in physics textbooks for the higher basic stage in the Hashemite Kingdom of Jordan. The sample consisted of the physics textbook for the ninth grade of the first and second parts for the scholastic year 2018/2019. In order to collect the data and achieve the aims of the study, the researcher used the descriptive method by analyzing the content based on an analysis card that was developed. The results of the study showed that the degree of inclusion of the skills of the twentyfirst century in the physics textbook for the ninth grade was generally low in all main skills, except the skills of critical thinking and problem-solving, where the results of the study cleared their high proportion. The results of the study also revealed low percentage of sub-skills of the $21^{\text {st }}$ century skills in a large number of them, in addition to the absence of inclusion number of sub-skills such as: Analyzing media, implementing innovations, creating media products, managaging products, guiding and leading others and being responsible to others.

(Keywords: $21^{\text {st }}$ Century Skills, Physics Textbooks, Higher Basic Stage)

وأصبحت "الكفـاءة الرقميـة" مفهومًا رئيسًا في الحوارات المختلفة

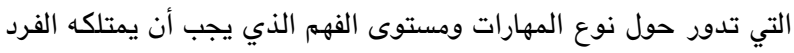

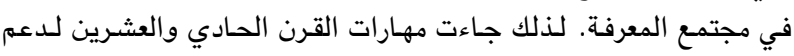

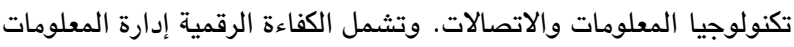

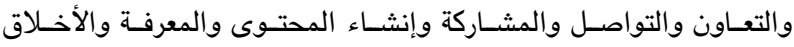

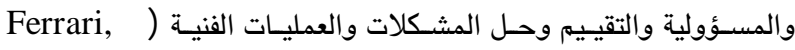

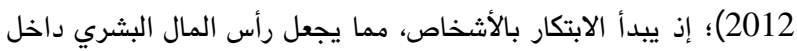

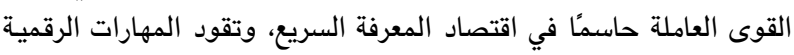

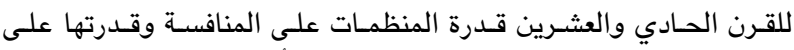

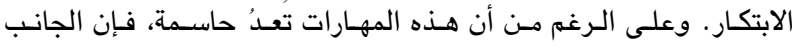

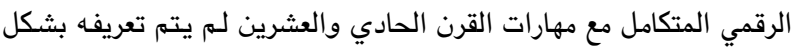

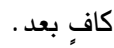

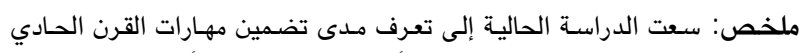

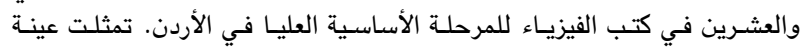

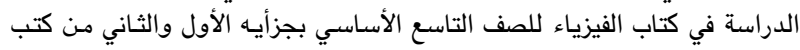

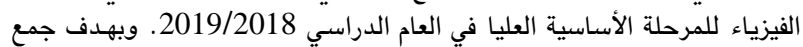

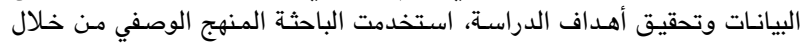

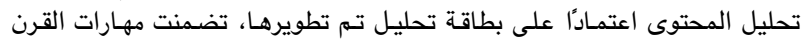

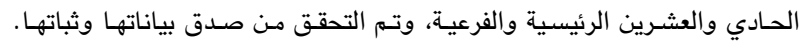

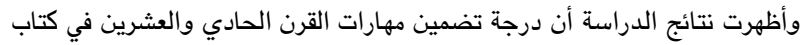

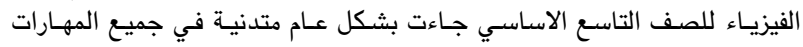

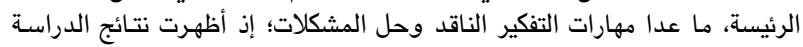

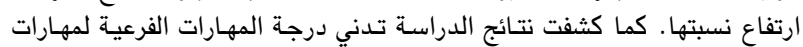

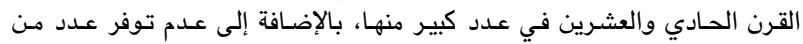

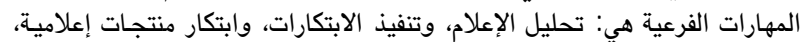
وإدارة المشروعات، وقيادة الآخرين، والمسؤولية عن الآخرين.

(الكلمـات المفتاحيـة: مهارات القرن الحـادي والعشرين، كتب الفيزيـاء، المرحلة الأساسية العليا)

مقدمـة: في ظل التطورات التقنية الحديثة، شـهد العالم تطورات

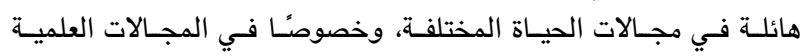

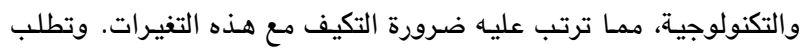
ذلك استحداث آليات يمكن من خلالها مسايرة التطور في كافة المجتمعات.

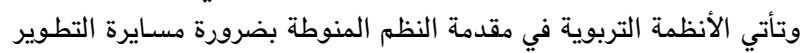

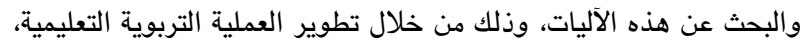

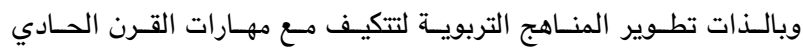
والعشرين، فكان لا بد من إعادة النظر في المناهج، ومعرفة مـدى الته ارتباطها مع توجهات القرن الحادي والعشرين.

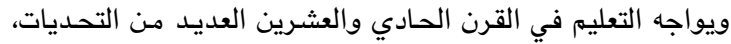

ومن أبرزها التحدي الثقافي والفكري والقيمي في عصر العولمي القية، ونمطية

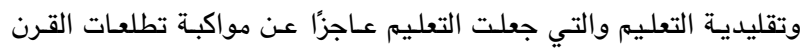

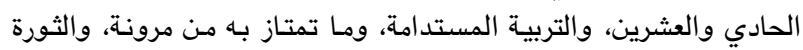

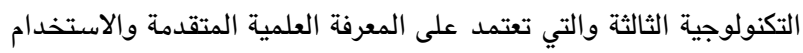

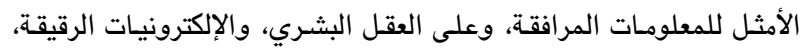

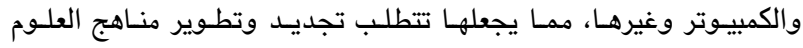

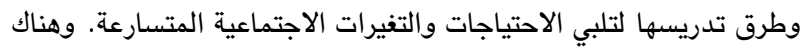

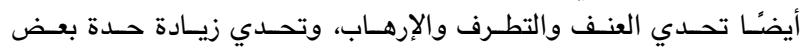

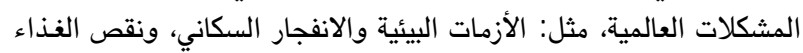
والدواء، والحروب المستمرة (Raphael \& Youssef, 2001).

$$
\text { ( ج حقوقة اليرموك، الأردن. }
$$


من التكيف مع التطورات الحديثة. وتم طرح إطار للتعلم يناسب متطلبات القرن الحادي والعشرين فيما يخص المتعلم، أُطلق عليه "إطار التعلم للقرن الحادي والعشرين"، كما في الثكل (1).
وقد ظهر اهتمام التربويين بمهارات القرن الحادي والعشرين عام 2002 من خلال مؤسسة الشراكة لمهارات القرن الحادي لمهري والعشرين (Partnership for the $21^{\text {st }}$ Century Skills)، التي هدفت إلى تحديد المهارات التي يجب أن يمتلكها المتعلم في

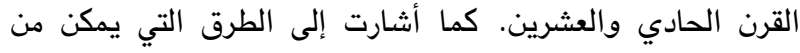
خلالها دمج تلك المهارات في المناهج حتى يتمكن الطلبة المتعلمون

الشكل (1): إطار التعلم للقرن الحادي والعشرين (Partnership for the $21^{\text {st }}$ Century Skills, 2009a: 211)

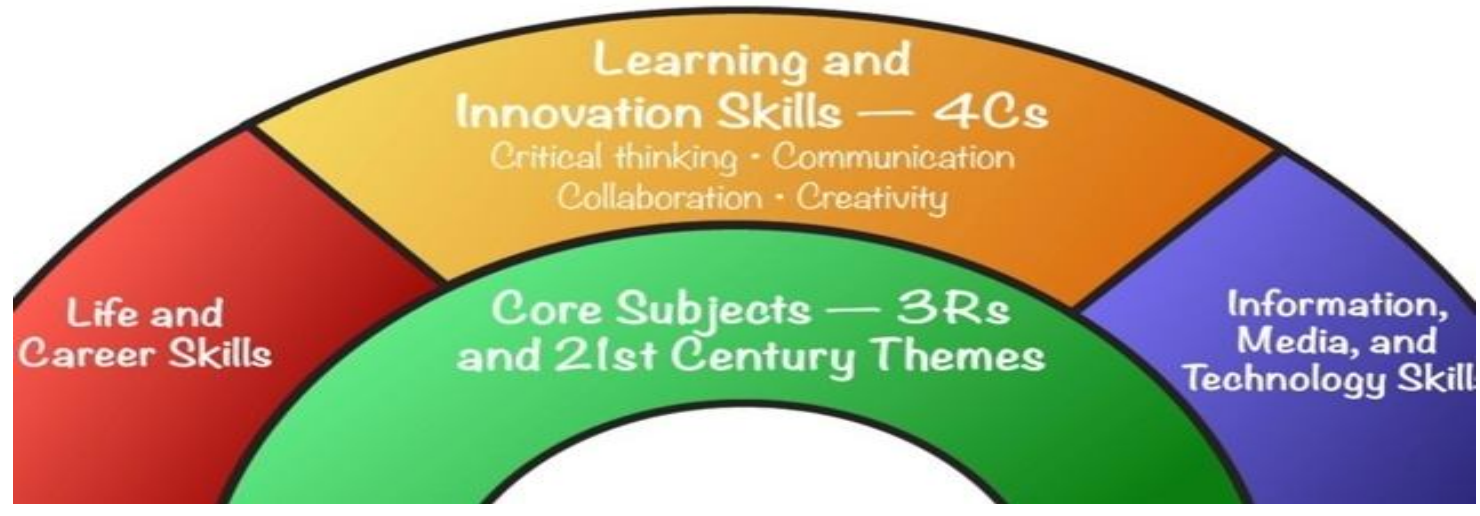

والابتكار والتفكير النقدي وحل المشكلات والاتصال والتعاون)،

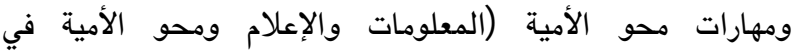

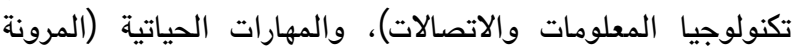

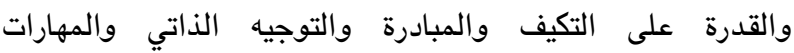

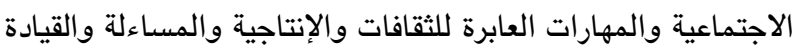

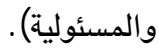

هذا في حين اقترحت مجموعات ومنظمات أخرى أطرًا مختلفة لمعايير القرن الحادي والعشرين. فقد صنف فريق خبراء

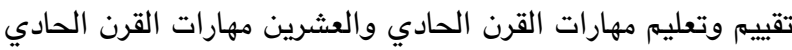

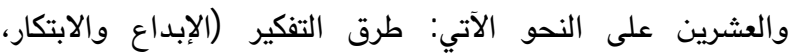

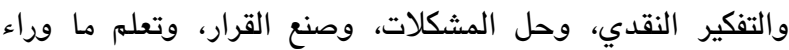

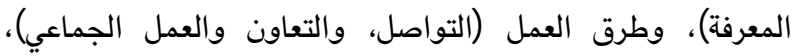

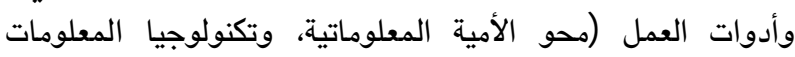
والاتصالات ومحو الأمية)، والحياة في العالم (الحياة والوظيفة، والمسؤولية الشخصية والاجتماعية) (Binkley et al., 2012). وينصب التركيز الرئيسي على ممارسات التعليم والتعلم لضمان إتقان الطلبة مهارات القرن الحادي والعشرين في الصف، كإعداد لحياة العمل (Leahy \& Dolan, 2010).

وعُرّقت خدمة الاختبارات التعليمية ( Educational (Testing Service: ETS, 2007 المعلومات، وتنظيمها وإدارتها، وتقييم جودتها وأهميتها وفائدتها،

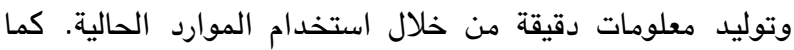

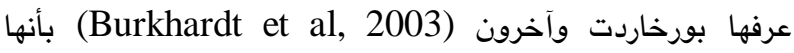
معرفة القراءة والكتابة في العصر الرقمي والتفكير الإبداعي
وقسَمت مؤسسة الثراكة مهارات القرن الحادي والعشرين إلى (

ثلاثة مجالات (Trilling \& Fadel, 2013) :

أولاً: مهارات التعلم والابتكار، وتشمل: التفكير الناقد وحل

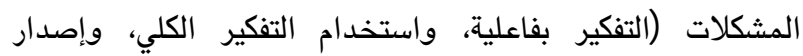
الأحكام واتخاذ القرارات، وحل المشكلات)، والتواصل والتعلية، والتعاون

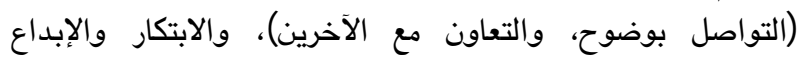

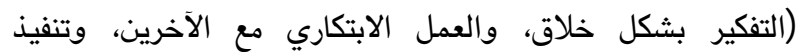

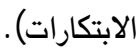

ثانيًا: مهارات تكنولوجيا المعلومات ووسائل الإعلام، وتشمل:

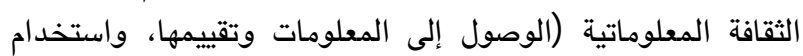

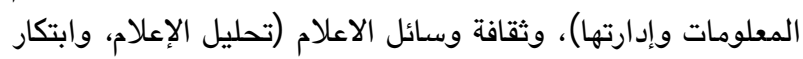

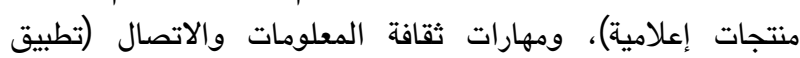

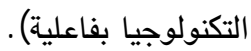

ثالثًا: مهارات الحياة والمهنة، وتشمل: مهارات المرونة والتكيف

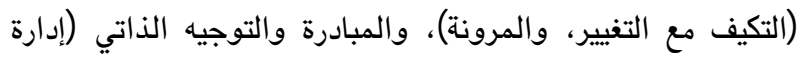

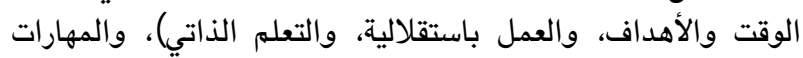

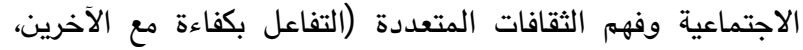
والعمل بفاعلية في فرق متنوعة)، ومهارات الإنتاجية والمساءلة وإكاءة

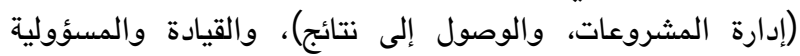
(قيادة الآخرين وتوجيههم، والمسؤولية عن الآخرين) .

وقد أضافت مؤسسة الشراكة لمهارات القرن الحادي

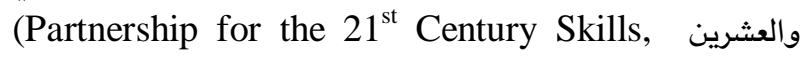
(2008 ثلاثة أنواع من المهارات هي: مهارات التعلم (الإبداع 
والتنفيذ والتواصل مع الطلبة في المواقف الصفية بشكل فعال .(Partnership for the $21^{\text {st }}$ Century Skills, 2009 b) وفي مجال تدريس العلوم، رأت الرابطة القومية لمعلمي العلوم أنه (National Science Teachers Association, 2011) لتحقيق جودة تعليم العلوم في ضوء مهارات القرن الحادي

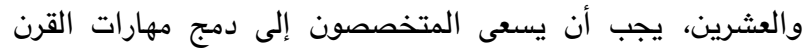

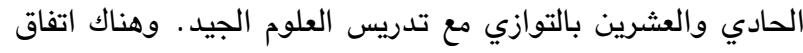

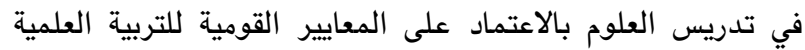

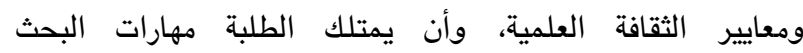

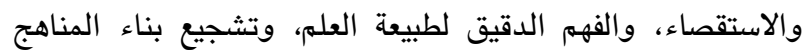

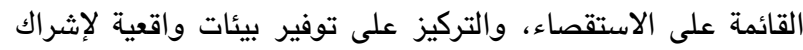

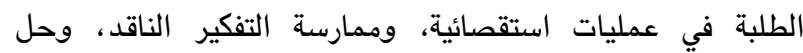
مشكلات واقعية، وتفسير الظواهر العلمية.

وقد حظيت مناهج العلوم بالعديد من الجهود التي بذلت لأجل

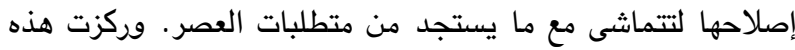
الجهود على هدفها المتمثل بضرورة أن يكون المتعلم مثقفاً علميًا .

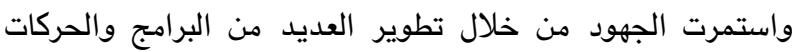

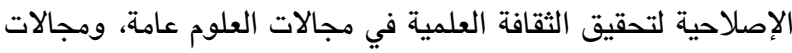

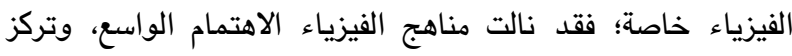

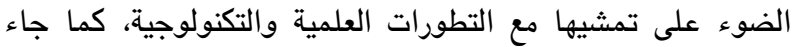

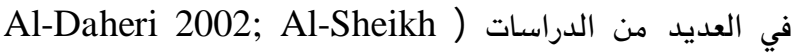
Eid, 2009; Al-Tweissat, 2011; Al-Yousef, 2011; .(Hammad, 2013

ولا شك في أن الاكتشافات العلمية في المجالات المختلفة

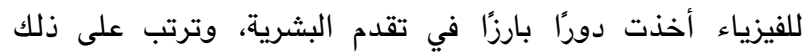

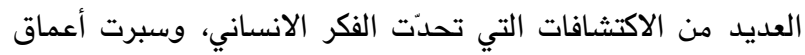
الكون (Zaanin \& Shabat, 2002). ونظرًا لأهمية علم الانمات العان

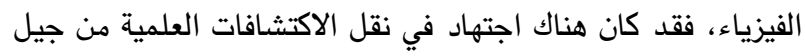
إلى آخر، وترك المجال مفتوحًا للعديد من الاكتشافات المستقبلية،

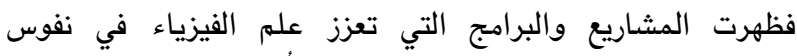
المتعلمين، وتقديم الفيزياء للطلبة بطرائق تيسر فهمهـ لأساسياته. وبمراجعة الدراسات السابقة التي أجريت في مجال مهارات

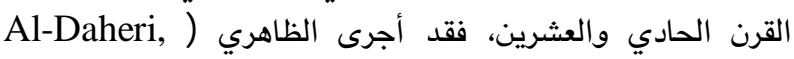

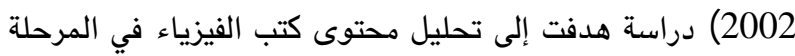

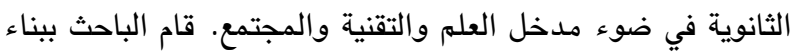

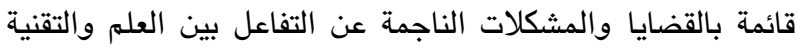

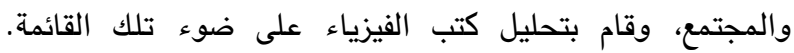

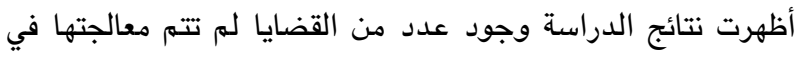

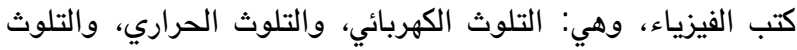

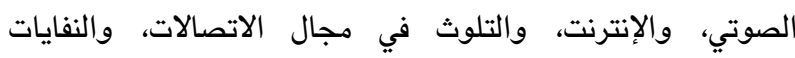

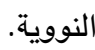

والتواصل الفعال والإنتاجية العالية. ومن جانهها، حددت شراكة

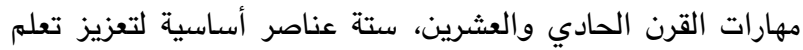
القرن الحادي والعشرين وهي: التركيز على المواد التهرين الأساسية،

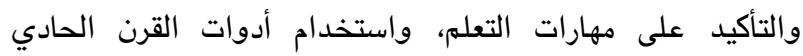

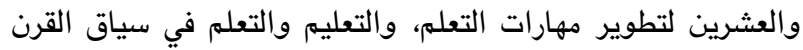

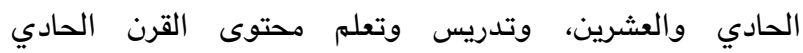

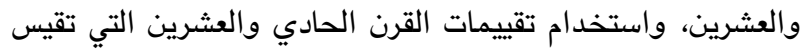
مهارات القرن الحادي والعشرين.

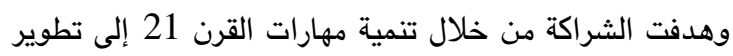

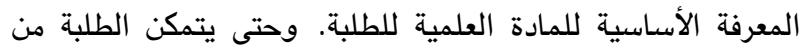

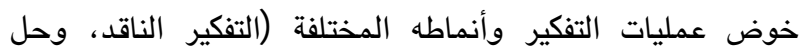

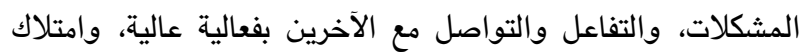

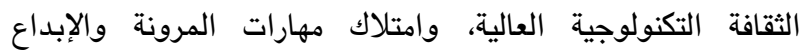
والابتكار). فلا بد من أن يكون الأساس في ذلك فئكات معرفة علمية

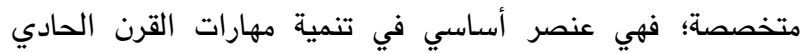
والعشرين ( Partnership for the $21^{\text {st }}$ Century Skills,

. (2009a

ولتحقيق الرؤية بضرورة أن تكون مهارات القرن الحادي

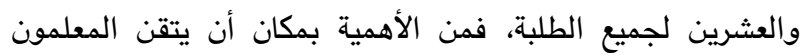

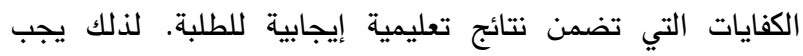

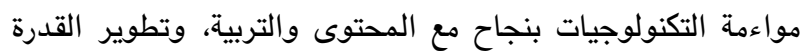

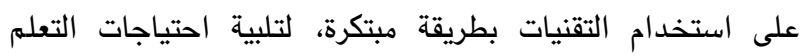

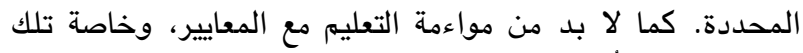

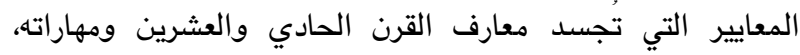

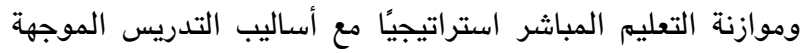

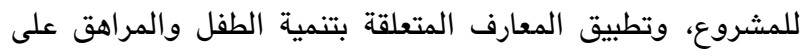

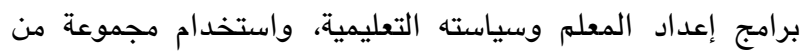

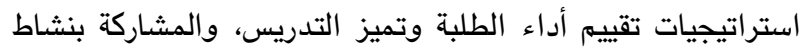

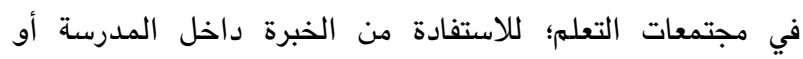

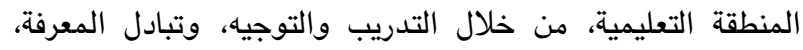

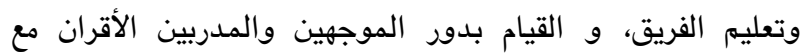

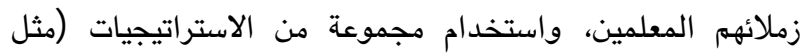
التقييمات التكوينية)، للوصول إلى الفروقات الفردية بين الطلبة،

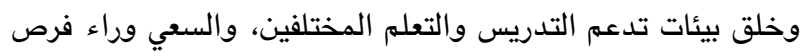
التعلم المستمر وتبني التعلم مدى الحياة (Greenhill, 2010). وقد تقدمت شراكة مهارات القرن الحادي والعشرين بمجموعة

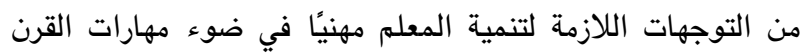

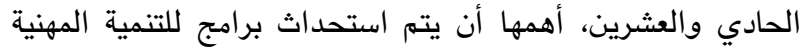

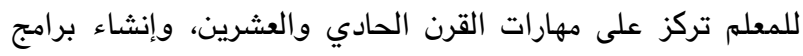
عمل تعاونية بين المعلمين والإداريين من أجل دعم التعليم المهان المهني

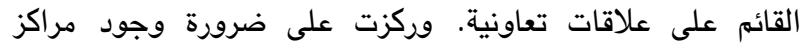

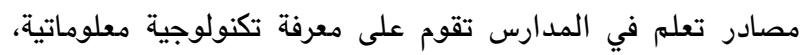

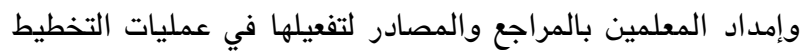


الفيزياء للصفين التاسع والعاشر لنتاجات التعلم. تكونت عينة الدراسة من (139) معلمًا ومعلمةً من معلمي الفيزياء في محافظة

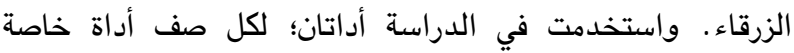

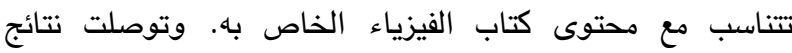
الدراسة إلى أن تقديرات المعلمين جاءت متوسطة لمحتوى كتاب

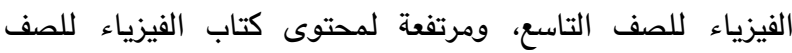

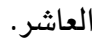

Hiong \& Osman, ) وهدفت دراسة هيونج وعثمان

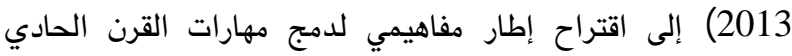
والعشرين في تعليم الأحياء في ماليزيا، من خلال منهاج متعدد إلى مهاري

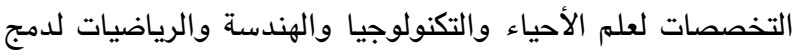
مهارات القرن الحادي والعشرين في المناهج الدراسية الحالية،

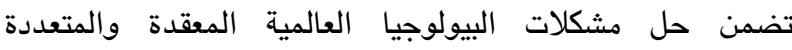

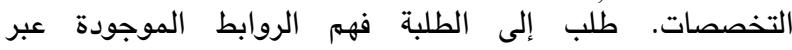

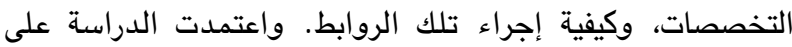

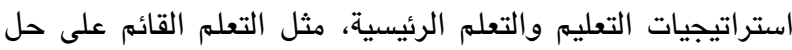

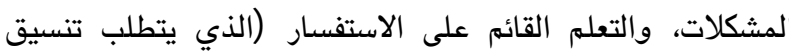

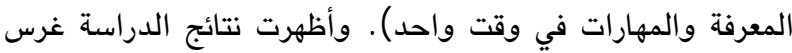

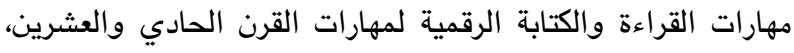

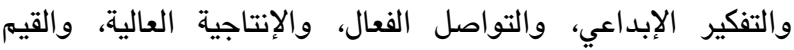
الروحية والنبيلة، لدى الطلبة الماليزيين.

وهدفت دراسة شلبي (Shalaby, 2014) إلى تحديد مهارات القرن الحادي والعشرين التي يمكن دمجها في مناهج العلوم

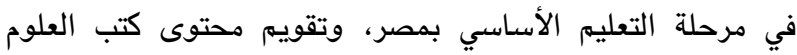

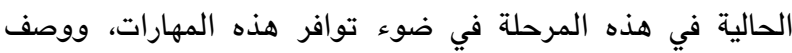

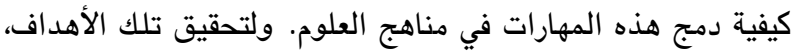

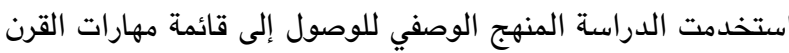

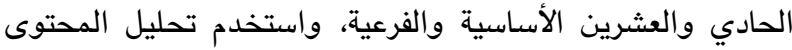

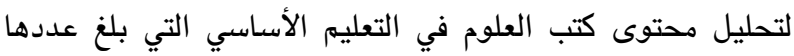
(6) كتب دراسية. وقد توصلت نتائج الدراسة إلى إطار مقترح يتكون من ثلاث مجموعات من المهارات (مهارات التعلم والابتكار،

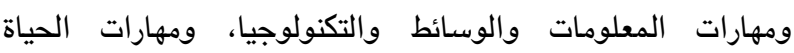

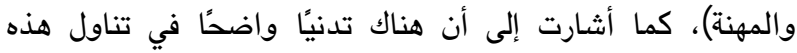

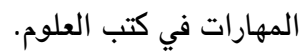

وأجرت سبحي (Sebhy, 2016) دراسة الهدف منها تحديد مدى تضمين مهارات القرن الحادي والعشرين في مناهج العلوم

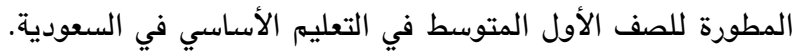

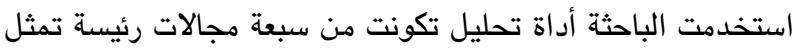

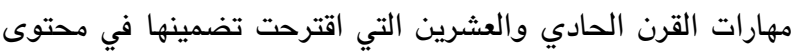

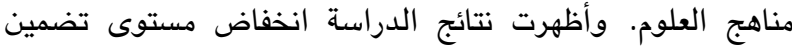
مهارات القرن الحادي والعشرين في محتوى مناهج العلوم بنسبة

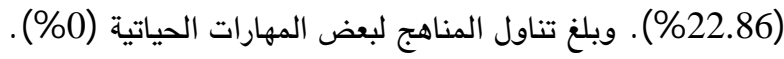

وأجرى حمودة (Hammoudeh, 2009) دراسة استخدم فيها الإطار اللفوي الاجتماعي في تحليل كتب العلوم المدرسية للتحقق من درجة توافر محتوى متخصص في العلوم (التصنيف)،

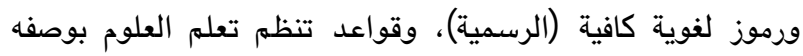

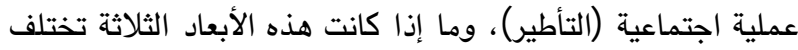
باختلاف الصف، والموضوع، والنص. تم تطبيق الدراسة على كتابي

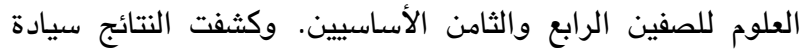
النصوص التقريرية على التجريبية والتاريخية، وأن التصنيف كان قويًا، وأعلى هذه النسب هو للمواضيع الفيزيائية. كما أظهرت النتائج تأطيرًا قويًا لكتب العلوم، وبخاصة في موضوع الفيزياء. وفي دراسة أجراها الثيخ عيد (Al-Sheikh Eid, 2009) بهدف التعرف على أبعاد التنور الفيزيائي لدى طلبة الصف الصفاد الحادي عشر، قام الباحث بإعداد قائمة بأبعاد التنور الفيزيائي، واختبارًا

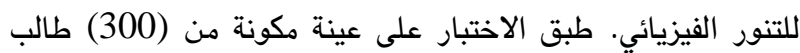

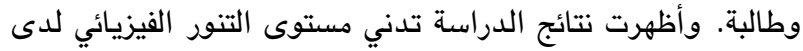

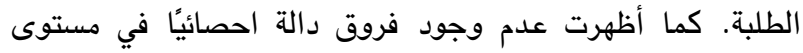
التنور لدى الطلبة تعزى إلى الجنس.

وهدفت دراسة الطويسات (Al-Tweissat, 2011) إلى في تحليل محتوى كتب الفيزياء في المرحلة الثانوية في ضوء متطلبات

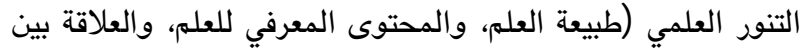
العلم والتكنولوجيا والمجتمع) . تكونت عينة الدراسة من كتابي

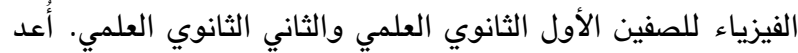
الباحث لهذه الدراسة أداة لتحليل المحتوى بحسب متطلبات الهي ولتول التنور العلمي وعناصرها . وأظهرت نتائج الدراسة أن مجالات التنور العلمي غير متوازنة في كتابي الصفين الأول والثاني الثانوييت. كما أن نسب تضمين متطلبات التنور العلمي في كتابي الفيزياء عينة الدراسة لا تتفق مع المعايير المحكية، باستثناء متطلب طبيعة العلم. كما جاءت نسب متطلب المحتوى المعرفي للعلم أعلى من النسبة

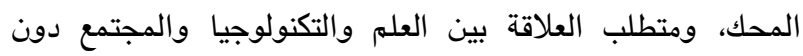
النسبة المحك. وأخيرًا جاء متطلب المحتوى المعرفي في المرتبة الأولى، ثم متطلب طبيعة العلم، وأخيرًا متطلب العلاقة بين العلم

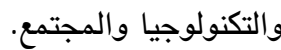

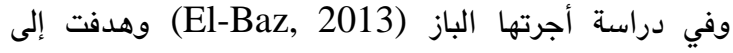

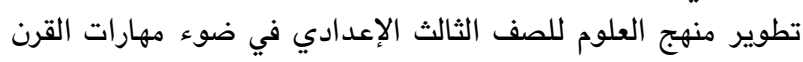

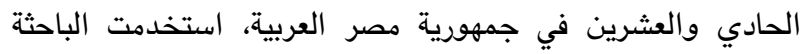

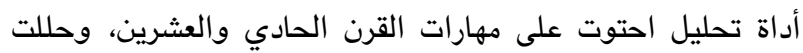

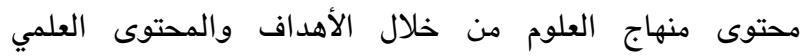

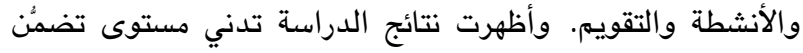

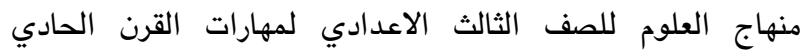
والعشرين.

ومن جانبها، أجرت حماد (Hammad, 2013) دراسة

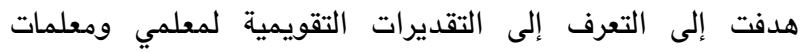
الفيزياء للصفين التاسع والعاشر، حول درجة ملاءمة محتوى كتب 
والسابع)، واستخدم تحليل المحتوى، وذلك بتطوير أداة تمثلت في

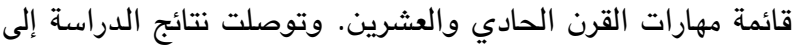

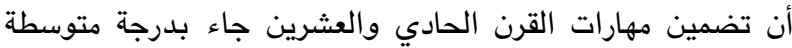

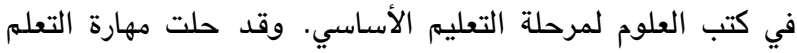

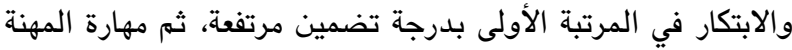

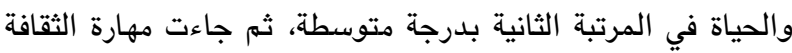

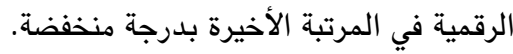

من خلال استعراض الدراسات السابقة، يُلاحظ اهتمام بشكل

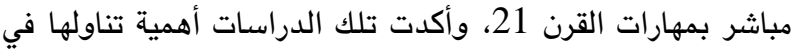

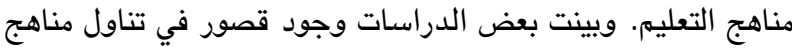

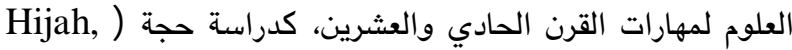

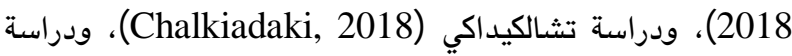
المنصور (Al-Mansor, 2018)، ودراسة لار ودورسن وديجيك (C) وداكيك

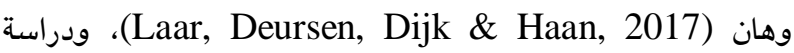

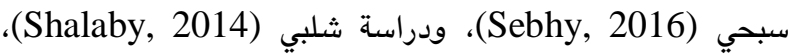

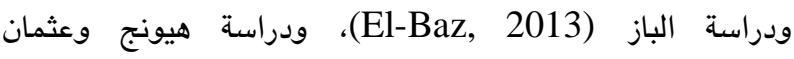

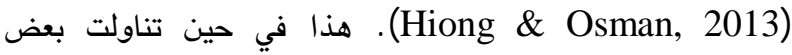
الدراسات مناهج العلوم بشكل عام ودرست آلية تضمينها مهارات

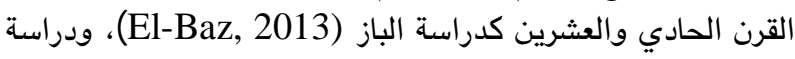
شلبي (Shalaby, 2014)، ودراسة سبحي (Sebhy,2016).

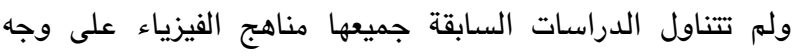
الخصوص، مما شجع الباحثة لإجراء الدراسة الحالية.

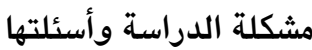

يواجه العالم تطورات سريعة في المجالات الاقتصادية، والتعليمية، والتقنية. ونظرًا لأهمية اكتساب المتعلمين لمهارات

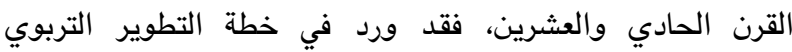
(Ministry of Education, 2017) الشامل للفرد في جميع جوانب شخصيته في ظل حتى يكون قادرًا

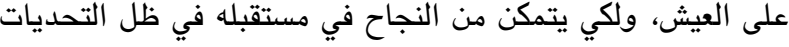

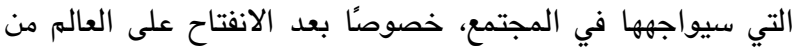
خلال التطورات التكنولوجية في القطاعات كافة.

كما أن هناك اعتقادًا لدى الطلبة بأن مادة الفيزياء صعبة الفهم

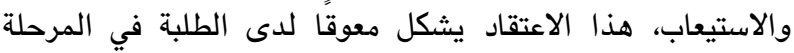

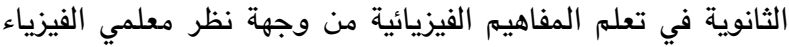

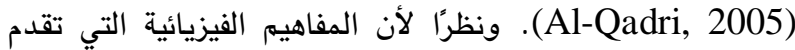

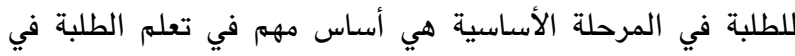

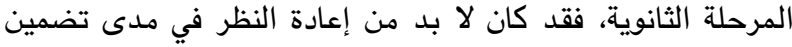

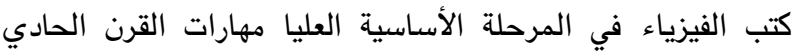
والعشرين حتى تتناسب مخرجاتها مع التطورات العالمية المختلفة. ولتحقيق ذلك، تم اختيار كتاب الفيزياء للصف التاسع الأساسي.

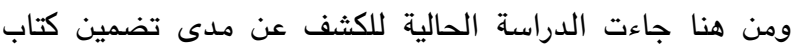
الفيزياء للصف التاسع الأساسي مهارات القرن الحادي والعشرين؛ إذاء

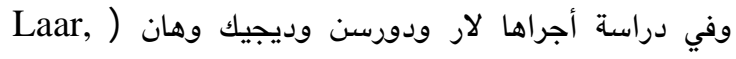

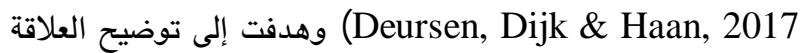
بين مهارات القرن الحادي والعشرين والمهارات الرقمية، تمت إجراء الرياء

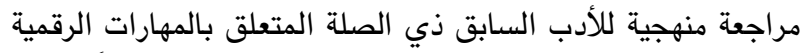

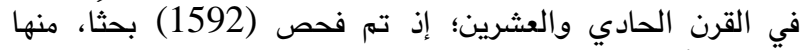

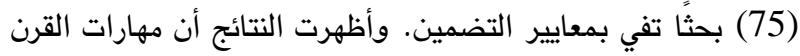

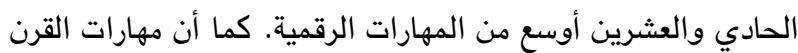

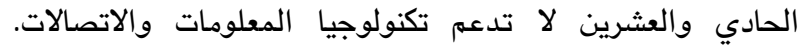

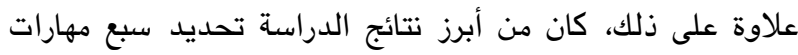

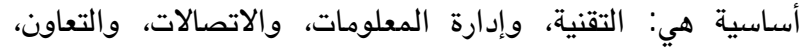

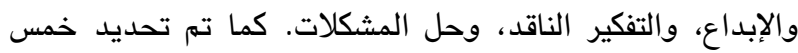

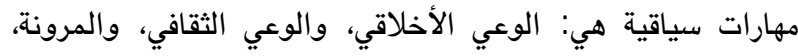
والتوجيه الذاتي، والتعلم مدى الحياة.

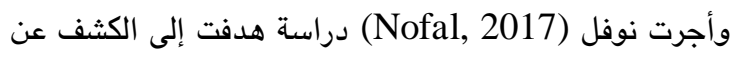

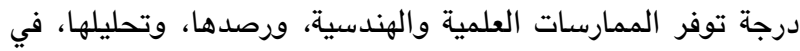

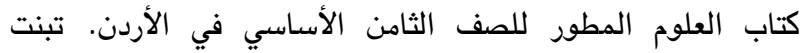

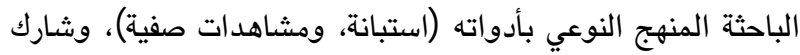

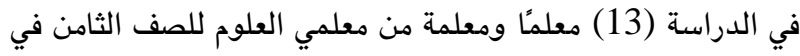

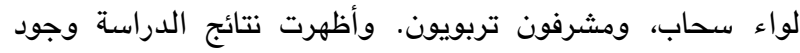

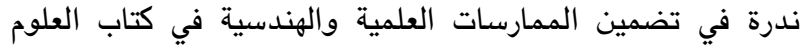
المطور للصف الثامن، إضافة إلى وجود ضعف في في إلمام المام المعلمين

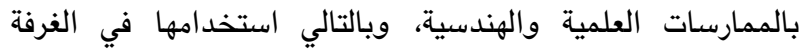

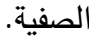
وأجرى تثالكيداكي (Chalkiadaki, 2018) دراسة عمل

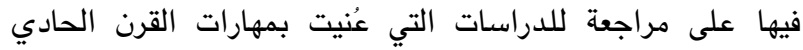

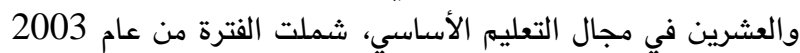

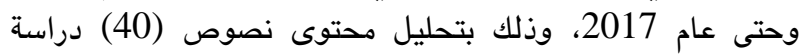

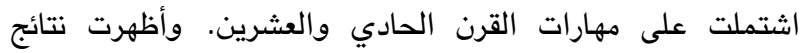

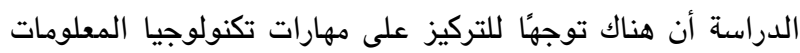
والاتصالات والعولمة والابتكار.

وهدفت دراسة حجة (Hijah, 2018) إلى استقصاء مدى تضمين كتب العلوم للمرحلة الأساسية للصفوف السابع والثامن الثنائ

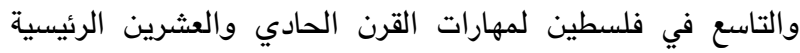
والفرعية. طور الباحث أداة تحليل تضمنت مهارات الترن التهاري وات القرن الحادين الرئية

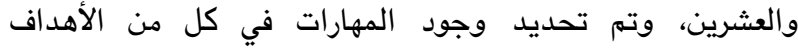

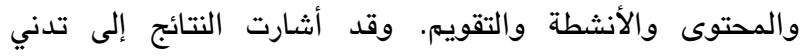
تضمين كتب العلوم مهارات القرن الحادي والعشرين العادين الرئيسية

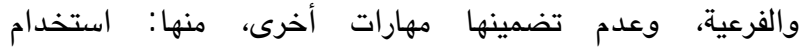
التكنولوجيا، والمبادرة، والتوجه الذاتي، والقيادة، والمسؤولية. وأجرت المنصور (AlMansor, 2018) دراسة هدفت إلى

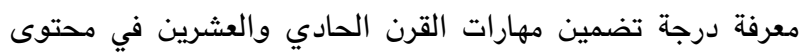

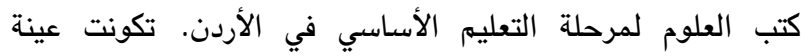

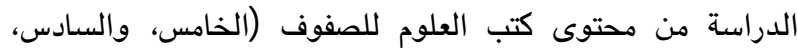




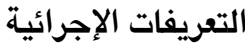

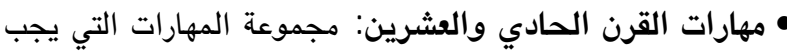

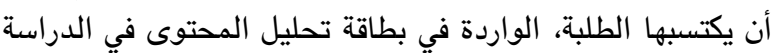

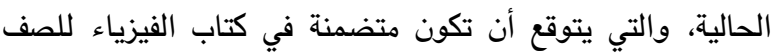

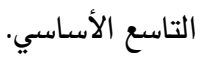

• تحليل المحتوى: تحديد درجة شمولية كتاب الفيزياء للصف

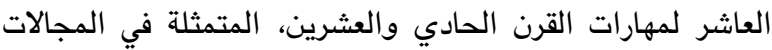

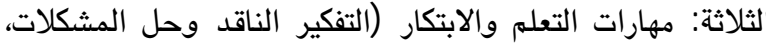

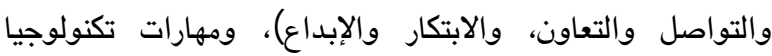

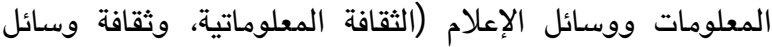

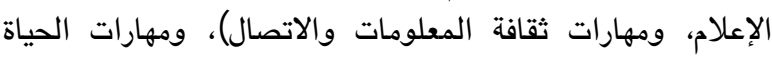

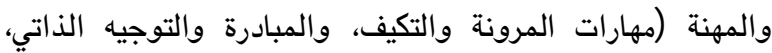
والمهارات الاجتماعية وفهم الثقافات المتعددة، ومهارات والاتهات والإنتاجية

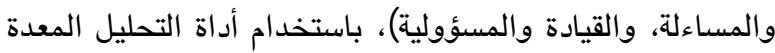

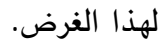

الطريقة منهج الدراسة

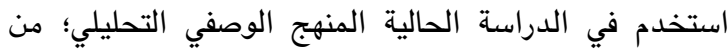

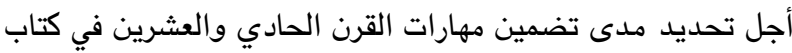

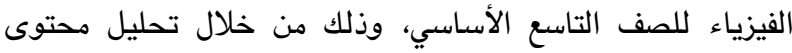

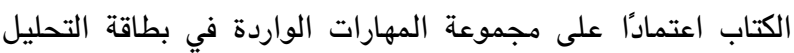
الخاصة بمهارات القرن الحادي والعشرين.

$$
\text { مجتمع الدراسة وعينتها }
$$

اشتمل مجتمع الدراسة على جميع كتب الفيزياء للمرحلة الأساسية العليا في العام الدراسي (2019/2018)، وتم الدئ اختيار

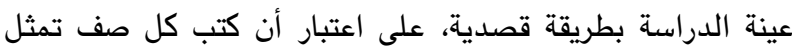

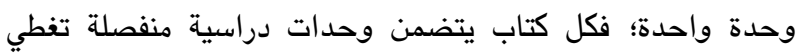

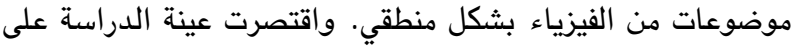

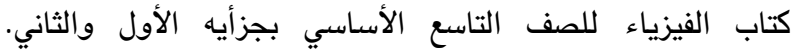
والجدول (1) يوضح مواصفات الكتاب.
تحاول الدراسة الاجابة عن السؤال الرئيس: ما مدى تضمين

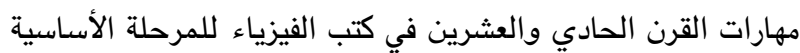
العليا في المملكة الأردنية الهاشمية؟ في في في وانبثق عن هذا السؤال الرئيس سؤالان فرعيان هما: السؤال الأول: ما مهارات القرن الحادي والعشرين الرئيسية والفرعية في كتاب الفيزياء للصف التاسع الأساسي؟ الفي التي

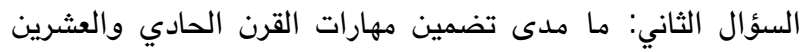
الرئيسية والفرعية في كتاب الفيزياء للصف التاسع الأساسي؟ تصائ أهمية الدراسة تأتي أهمية الدراسة الحالية تماشيًا مع حركات تطوير المناهج

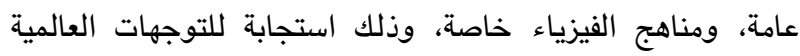
حول أهمية تضمين مناهج العلوم مهارات القرن الحادي والعادية والعشرين.

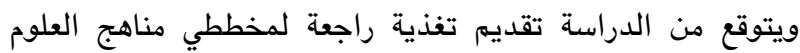

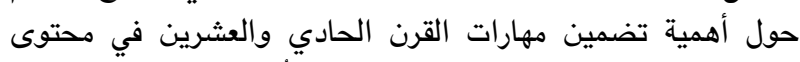

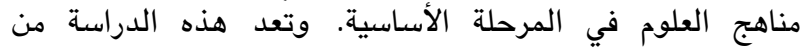

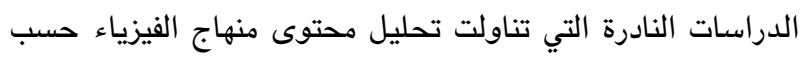

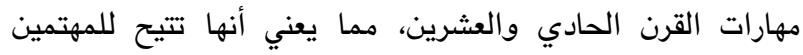
تناول تحليل المحتوى بنفس الطريقة في دراسات أخرى. كما يتوقع أن تفيد نتائجها وتوصياتها في تطوير مناهج الفيزياء . حدود الدراسة ومحدداتها تم تحليل محتوى كتاب الفيزياء المطور للصف التاسع

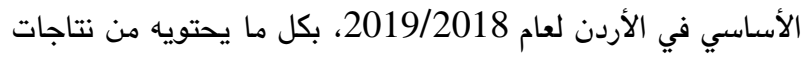

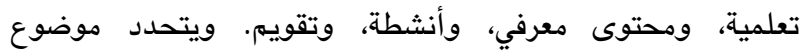

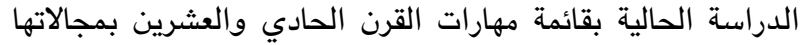
ومؤشراتها. كما أن صدق أداة الدراسة، وثبات عملية التحليل،

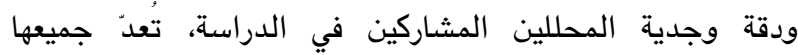

\begin{tabular}{|c|c|c|c|c|c|c|c|c|}
\hline التقويم & الأنشطة & الفقرات & الأهداف & الدروس & الوحدات & الصفحات & الجزء & كتاب \\
\hline 109 & 11 & 84 & 41 & 15 & 2 & 135 & الأول & الصف \\
\hline 83 & 13 & 65 & 31 & 9 & 2 & 106 & الثاني & التاسع \\
\hline
\end{tabular}

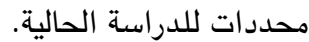

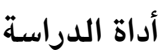

عملت الباحثة على إعادة ترجمتها وعرضها على مجموعة من

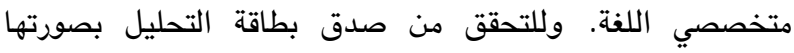
الأولية، تم عرضها على عشرة من المحكمين من أعضاء هيئة
تم استخدام بطاقة تحليل المحتوى التي أعدها تريلنج وفادل (Trilling \& Fadel, 2009)، وتبنتها عدد من الدئ الدراسات (El-baz, 2013; Shalaby, 2014; Hijah, 2018) 
تحليل المحتوى، بما فيها من مهارات رئيسية ومهارات فرعية ومؤشرات.

ولأغراض التحقق من دلالات الثبات، تم استخدام معادلة هولستي (Holsti) لحساب ثبات الاتساق عبر المحللين، من خلات التال

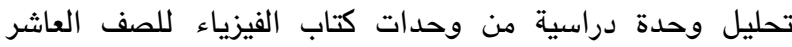

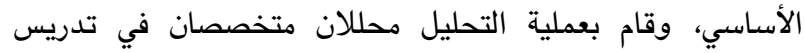
الفيزياء. ويوضح الجدول (2) معاملات الثبات.
التدريس في جامعة اليرموك، ومن ذوي الاختصاص في مناهج

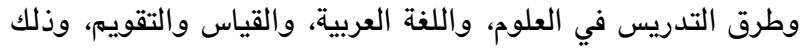

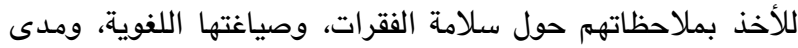

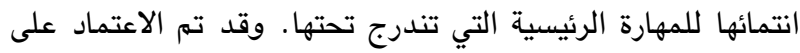

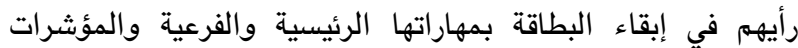

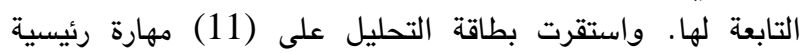

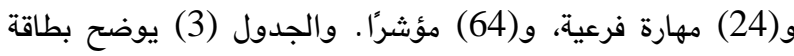

جدول (2): عدد نقاط الاتفاق بين المحللين ومعاملات ثبات تحليل كتاب الفيزياء عينة الدراسة على مستوى المهارات الرئيسية

\begin{tabular}{|c|c|c|c|c|c|c|c|c|c|c|c|c|}
\hline المجموع & الحهادية & العاشرة المهارة & التاسعة & الثامهارة & السـابعة المهارة & السادسة & الخامسة المهارة & الرابعة & الثالثة & الثهارة & الأولى & \\
\hline 173 & 0 & 0 & 4 & 15 & 7 & 11 & 11 & 14 & 17 & 41 & 53 & الأول \\
\hline 208 & 1 & 3 & 13 & 25 & 11 & 17 & 16 & 8 & 10 & 59 & 46 & الثاني \\
\hline 153 & 0 & 0 & 4 & 15 & 7 & 11 & 11 & 8 & 10 & 41 & 46 & الاتفاق \\
\hline 0.81 & 0 & 0 & 0.56 & 0.60 & 0.78 & 0.65 & 0.73 & 0.89 & 0.83 & 0.69 & 0.85 & معامل \\
\hline
\end{tabular}

4. تحديد مدى توافر مهارات القرن الحادي والعشرين وفقًا لعدد

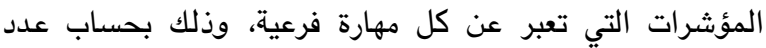

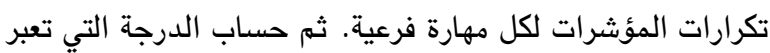
عن كل مهارة رئيسية بجمع تكرارات المؤشرات التابعة لكل مهارة

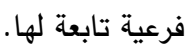

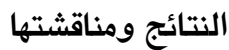
أولاً: النتائج المتعلقة بالسؤال الأول: ما مهارات القرن الحادي

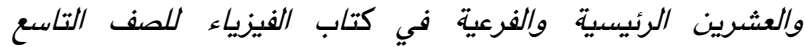
الأساسي؟ والعشرين تتمثل الإجابة عن هذا السؤال في تحديد مجالات ومؤشرات

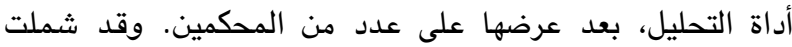

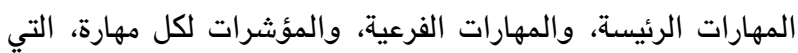
تم اعتمادها ضمن أداة التحليل، كما هو موضح في الجدول (3).
يلاحظ من الجدول 2 أن قيمة معامل الثبات الكلية بلغت

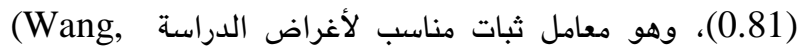
.2011)

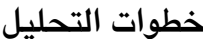

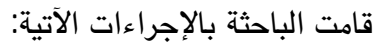

1. تحديد كتاب الصف التاسع الأساسي من مادة الفيزياء، وذلك ليكون عينة التحليل، ويشمل التحليل جزأيه الأول والثاني. 2. تحديد فئات التحليل، التي اشتملت على: الأهداف، والمحتوى، ولئ، والأنشطة، والتقويم.

3. تحديد وحدة التحليل لكل فئة؛ إذ تمثلت في الهدف كوحدة تحليل للأهداف، والفقرة كوحدة تحليل للمحتوى، والنشاط النياط كوحدة تحليل للأنثطة، والسؤال كوحدة تحليل للتقويم. 
جدول (3): بطاقة تحليل محتوى كتاب الفيزياء للصف التاسع الأساسي وفق مهارات القرن الحادي والعشرين

\begin{tabular}{|c|c|c|}
\hline 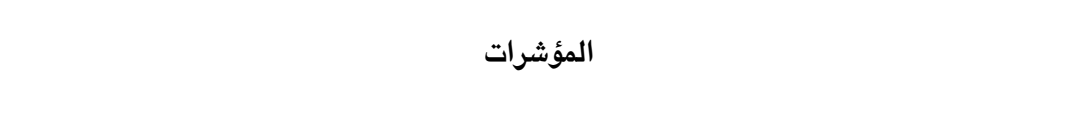 & 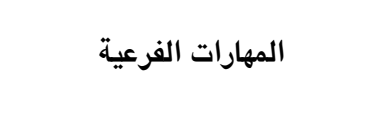 & 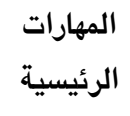 \\
\hline يستخدم أنواءًا مختلفة من التفكير (الاستقراء، الاستنباط...).... بما يناسب الموقف التعليمي. & التفكير بفاعلية & \multirow{9}{*}{ 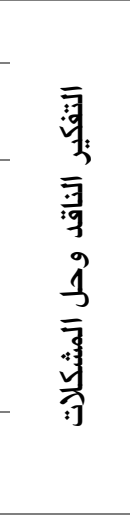 } \\
\hline يحلل كيف تتفاعل أجزاء من الكل لإنتاج مخرجات نهائية في نظم معقدة. & استخدام التفكير الكلي & \\
\hline يحلل ويقوم الأدلة، والحجج، والفروض، والمعتقدات بفاعلية. & \multirow{5}{*}{ واتخاذ القرارات الأحكام } & \\
\hline يحلل ويقوم وجهات نظر أساسية وبديلة. & & \\
\hline يجمع ويربط بين المعلومات والحجج. & & \\
\hline يفسر البيانات ويتوصل لاستتتاجات قائمة على التحليل. & & \\
\hline يفكر تفكيرًا ناقدًا في خبرات وعمليات التعلم. & & \\
\hline يحل أنواعًا مختلفة من المشكلات غير المألوفة بطرق تقليدية وطرق إبداعية. & \multirow{2}{*}{ 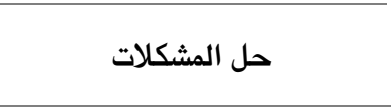 } & \\
\hline يسأل أسئلة مهمة توضح وجهات نظر متعددة لحلول أفضل. & & \\
\hline يعبر عن الأفكار والآراء بشكل فعال باستخدام مهارات التواصل الثفهية، والمكتوبة، وغير اللفظية في & \multirow{9}{*}{ 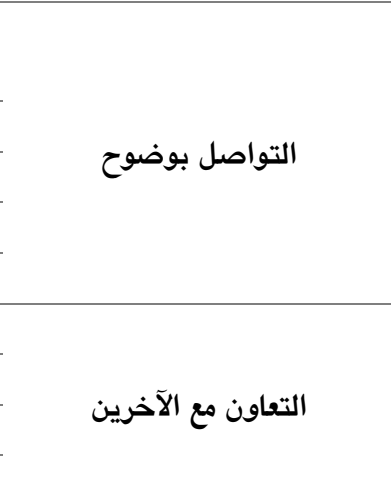 } & \multirow{9}{*}{$\begin{array}{l}\text { 高 } \\
\frac{9}{3} \\
\text { 商 } \\
.3 \\
.3\end{array}$} \\
\hline يستمع بفاعلية للوصول إلى المعنى. & & \\
\hline يستخدم التواصل لتحقيق أهداف متنوعة (الإخبار، التوجيه، الدافعية، الحث، الإقناع). & & \\
\hline يستفيد من الوسائط المتعددة والتكنولوجيا، ويعرف كيف يحكم على فاعليتها وتقييم تأثيرها. & & \\
\hline يتواصل بفاعلية في بيئات متنوعة متعددة اللفات. & & \\
\hline يعمل بفاعلية واحترام مع مجموعات متنوعة. & & \\
\hline يبدي مرونة ورغبة في أن يكون متعاونُا. & & \\
\hline يقدم التنازلات الضرورية لتحقيق هدف نهائي مشترك. & & \\
\hline \multirow{2}{*}{\multicolumn{3}{|c|}{ 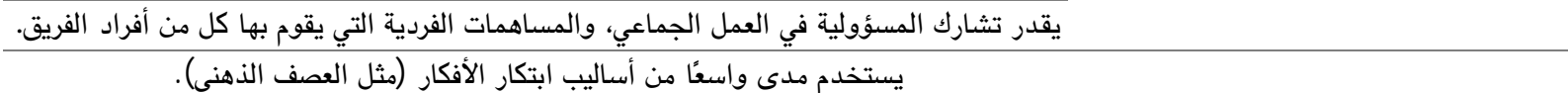 }} \\
\hline & & \\
\hline يبتكر أفكارًا جدية وقيمة على نحو تدريجي أو جزئي. & \multirow[t]{2}{*}{ 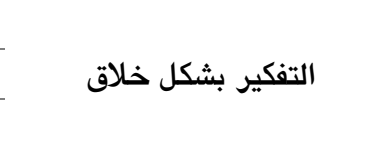 } & \multirow{7}{*}{ 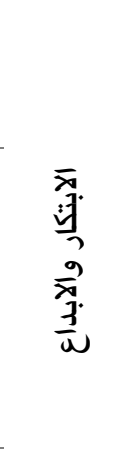 } \\
\hline يوسع، وينقح، ويحلل، ويقيم أفكاره لتحسين ومضاعفة جهوده الابتكارية. & & \\
\hline يطور أفكارًا جديدة وينفذها، ويتواصل مع أفكار الآخرين بفاعلية. & \multirow{5}{*}{ 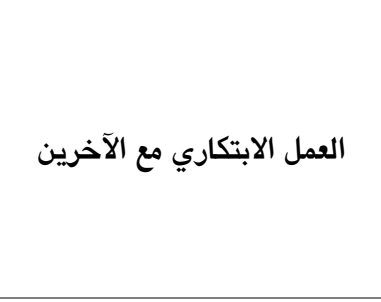 } & \\
\hline يكون منفتحًا ومتجاوبًا مع وجهات النظر الجديدة والمتنوعة، ويدمج مدخلات المجموعة والتغذية & & \\
\hline 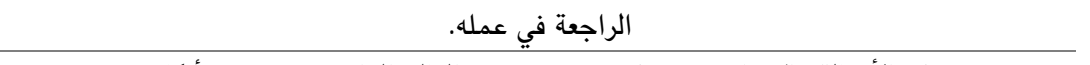 & & \\
\hline يبرهن على الأصالة والإبداع في عمله، ويفهم حدود العالم الواقعي عند تبني أفكار جديدة. & & \\
\hline ينظر إلى الفثل عل أنه فرصة للتعلم، ويفهم أن الابتكار والإبداع عملية دائرية طويلة الأمد تتكون & & \\
\hline يعمل على الأفكار المبتكرة للوصول إلى إسهام ملموس مفيد للمجال الذي يعمل فيه الابتكار. & 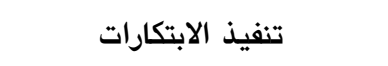 & \\
\hline يصل إلى المعلومات بكفاءة (الوقت) وبفاعلية (المصادر). & \multirow{2}{*}{ الوصول إلى المعلومات وتقييمها } & \multirow{5}{*}{ 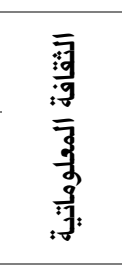 } \\
\hline يقيم المعلومات تقيمًا نقديًا. & & \\
\hline يستخدم المعلومات بدقة وإبداع في التقنية أو المشكلة التي يتناولها. & \multirow{3}{*}{ استخدام المعلومات وإدارتها } & \\
\hline يدير تدفق المعلومات من مصادر واسعة متنوعة. & & \\
\hline يطبق الفهم الجوهري للقضايا الأخلاقية القانونية المرتبطة بالوصول إلى المعلومات واستخدامها. & & \\
\hline يفهـم كيف ولماذا تبنى الرسالة الإعلامية والهدف منها. & \multirow{5}{*}{ تحليل الإعلام } & \multirow{6}{*}{ 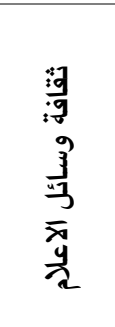 } \\
\hline يفهم كيف يمكن تفسير الرسائل بطرق مختلة، وكيف يتم تضمين القيم ووجهات النظر أو استبعادها، & & \\
\hline وكيف يمكن أن تؤثر وسائل الإعلام في المعتقدات والسلوكيات. & & \\
\hline يطبق الفهم الجوهري للقضايا الأخلاقية والقانونية المتعلقة بالوصول إلى الرسائل الإعلامية & & \\
\hline إستخداهها ويطبق القوانين المتعلقة بها. & & \\
\hline يفهم ويستخدم الأدوات والخصائص والأعراف الأكثر ملاءمة للإنتاج الإعلامي. & 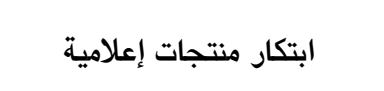 & \\
\hline
\end{tabular}




\begin{tabular}{|c|c|c|}
\hline 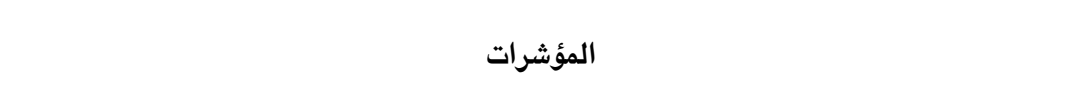 & 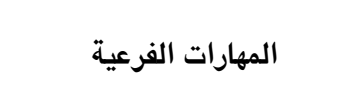 & المئيسية المارات \\
\hline يستخدم التكنولوجيا كأداة للبحث، والتنظيم، والتقييم وتوصيل المعلومات. & \multirow{5}{*}{ ت تطبيق التكنولوجيا بفاعلية } & \multirow{5}{*}{ 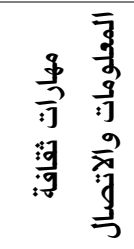 } \\
\hline يستخدم التكنولوجيا الرقمية وأدوات التواصل وشبكات التواصل الاجتماعي بنجاح للوصول إلى إدارة & & \\
\hline المعلومات وتكاملها وتقييمها للعمل بنجاح في اقتصاد المعرفة. & & \\
\hline يطبق فهمًا أساسيًا للقضايا الأخلاقية والقانونية المتعلقة بالوصول إلى المعرفة التكنولوجية & & \\
\hline واستخد امها. & & \\
\hline يتكيف مع الأدوار والمسؤوليات، وجداول وسياسات متنوعة، وسياقات مختلفة. & \multirow{2}{*}{ التكيف مع التفيير } & \multirow{6}{*}{ 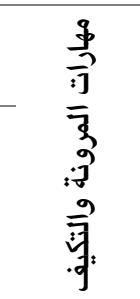 } \\
\hline يعمل بفاعلية في جو من الغموض وتغير الأولويات. & & \\
\hline يستثمر التفذية الراجعة بفاعلية. & \multirow{4}{*}{ 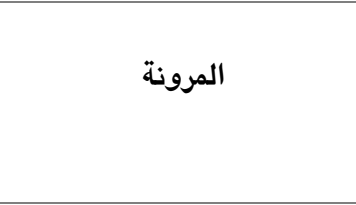 } & \\
\hline يتعامل بإيجابية مع النجاح والإخفاق والنقد. ي & & \\
\hline يفهم وجهات نظر واعتقادات متنوعة، ويتفاوض بشأنها، ويقيمها للوصول إلى حلول عملية، خصوصًا & & \\
\hline 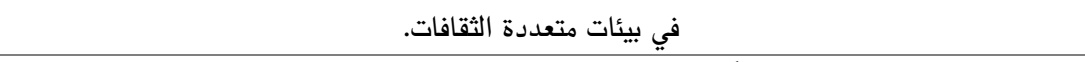 & & \\
\hline يصوغ أهداف بمعايير نجاح ملموسة وغير ملموسة. & \multirow{2}{*}{ 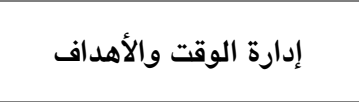 } & \multirow{8}{*}{ 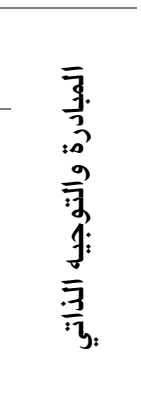 } \\
\hline يحقق التوازن بين الأهداف قصيرة المدى والأهداف الاستراتيجية طويلة المدى. & & \\
\hline يراقب المهام ويحددها في أولويات وينجزها دون إشراف مباشر. & \multirow{6}{*}{ 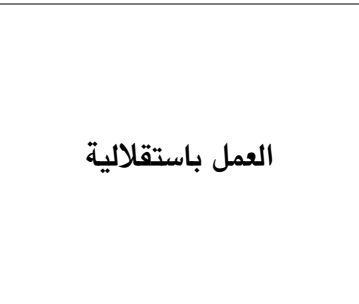 } & \\
\hline يكون متعلمًا موجهًا ذاتيًا. & & \\
\hline يتجاوز إتقان المهارات الأساسية ومتطلبات المنهج إلى استكثاف وتوسيع التعلم الثخصي والفرص & & \\
\hline ل لاكتساب الخبرة. & & \\
\hline ليرهن على الالتزام بالتعلم كعملية مستمرة مدى الحياة. & & \\
\hline يتأمل بطريقة ناقدة في خبراته الماضية لتوجيه تقدمه في المستقبل. & & \\
\hline يعرف متى من المناسب أن يتكلم ومتى يستمح. & \multirow{2}{*}{ 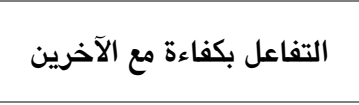 } & \multirow{5}{*}{ 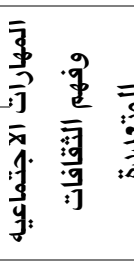 } \\
\hline ل يقود فرق العمل بطريقة مهنية، ويوجه سلوكها بأسلوب ملائم. & & \\
\hline يحترم الاختلافات الثقافية ويعمل بكفاءة مع الناس من مختلف الخلفيات الاجتماعية والثقافية. & \multirow{3}{*}{ العمل بفاعلية في فرق متنوعة } & \\
\hline يستجيب بعقل متفتح لمختلف الأفكار والقيم. & & \\
\hline يستفيد من الاختلافات الاجتماعية والثقافية لخلق أفكار جديدة وزيادة كل من الإبداع وجودة العمل. & & \\
\hline يضع الأهداف ويحققها، حتى في حالة المعيقات وضغط المنافسة. & \multirow{2}{*}{ إدارة المشر } & \multirow{9}{*}{ 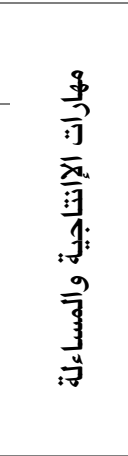 } \\
\hline يضع أولويات، ويخطط، ويدير العمل لتحقيق النتائج المرجوة. & & \\
\hline يعرض سمات إضافية مرتبطة بإنتاج منتجات عالية الجودة بما في ذلك القدرة على العمل الإيجابي & \multirow{7}{*}{ الوصول إلى نتائج } & \\
\hline 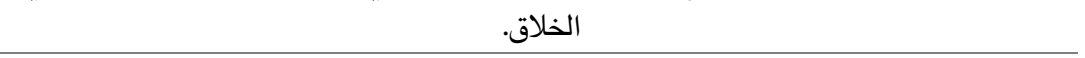 & & \\
\hline يدير الوقت والمشروعات بفاعلية. & & \\
\hline يقوم بمهام متعددة. & & \\
\hline يشارك بفاعلية، وواقعية، ودقة في العمل. & & \\
\hline يتعاون ويتاززر بفاعلية مع الفريق. & & \\
\hline يقدر التنوع بين أفراد الفريق، ويتحمل المسؤولية عن النتائج. & & \\
\hline يستخدم مهارات الاتصال الثخصية ومهارات حل المشكلات للتأثير على الآخرين وتوجيهمم نحو & \multirow{4}{*}{ توجيه الآخرين وقيادتهم } & \multirow{5}{*}{ 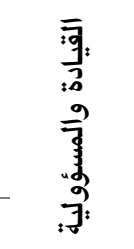 } \\
\hline الهدف. & & \\
\hline يستثمر نقاط القوة عند الآخرين في تحقيق الأهداف المشتركة. & & \\
\hline يرهن على السلوك المستقيم والأخلاقي في استخدام قوة التأثير. & & \\
\hline يتصرف بمسؤولية نحو اهتمامات المجتمع الأكبر ومصالحه. & 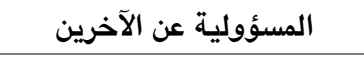 & \\
\hline
\end{tabular}

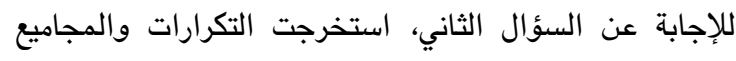

والنسب المئوية لمهارات القرن الحادي والعشرين الرئيسية والفرعية

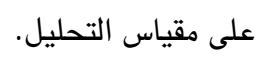

ثانيًا: النتائج المتعلقة بالسؤال الثاني: ما مدى تضمين مهارات القرن الحادي والعشرين الرئيسية والفرعية في كتاب الفيزياء للصف التاسع الأساسي؟ 


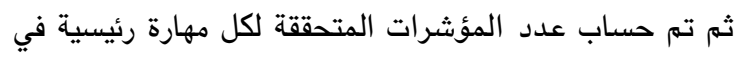

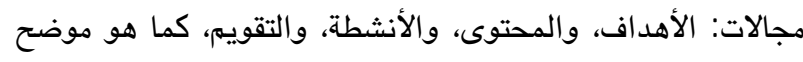

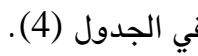

أ. نتائج التحليل المتعلقة بمهارات القرن الحادي والعشرين الرئيسية

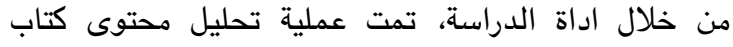
الفيزياء للصف التاسع الأساسي بجزأيه الأول والثاني.

جدول (4): مواصفات كتاب الفيزياء للصف التاسع والنسب المئوية لمهارات القرن الحادي والعشرين الرئيسية والفرعية

\begin{tabular}{|c|c|c|c|c|c|c|c|c|c|c|c|}
\hline \multirow{3}{*}{ 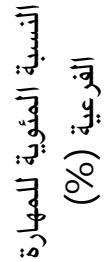 } & \multirow{3}{*}{ 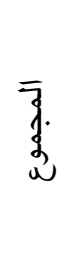 } & \multicolumn{2}{|c|}{ التقويم } & \multicolumn{2}{|c|}{ الأنشطة } & \multicolumn{2}{|c|}{ المحتوى } & \multicolumn{2}{|c|}{ الأهداف } & \multirow{3}{*}{ المؤشرات - عدد } & \multirow{3}{*}{ الرئيسية } \\
\hline & & الثزء الثي & الأول & الثزء الثاني & الأجزء & الثزاني & الأول & الثزء & الأول & & \\
\hline & & المؤشرات & المؤشرات & المتحقشقات & المؤشرات & المتحقشقات & المؤشرات & المؤشرات & المؤشرات & & \\
\hline 89.7 & 61 & 9 & 9 & 10 & 4 & 12 & 5 & 10 & 2 & $\underline{9}$ & وحل المشكلات \\
\hline 33.82 & 23 & 0 & 0 & 4 & 17 & 1 & 1 & 0 & 0 & $\underline{9}$ & والتعاصن \\
\hline 10.29 & 7 & 0 & 0 & 4 & 0 & 1 & 1 & 0 & 1 & $\underline{8}$ & الابتكار والإبداع \\
\hline 16.17 & 11 & 0 & 0 & 4 & 0 & 7 & 0 & 0 & 0 & $\underline{5}$ & المعلوماتية \\
\hline $\mathbf{0}$ & 0 & 0 & 0 & 0 & 0 & 0 & 0 & 0 & 0 & $\underline{5}$ & ثقافة وسائل \\
\hline 4.41 & 3 & 0 & 0 & 0 & 0 & 1 & 0 & 0 & 2 & $\underline{3}$ & ثقافة المعلومات \\
\hline 10.29 & 7 & 0 & 1 & 0 & 0 & 2 & 1 & 2 & 1 & $\underline{5}$ & المرونة والتكيف \\
\hline 23.52 & 16 & 0 & 0 & 8 & 0 & 4 & 0 & 4 & 0 & $\underline{7}$ & والتوجيه الذاتي \\
\hline 4.41 & 3 & 0 & 1 & 1 & 1 & 0 & 0 & 0 & 0 & $\underline{4}$ & الاجتماعية وفهم الثمارات \\
\hline 11.76 & 8 & 0 & 0 & 6 & 2 & 0 & 0 & 0 & 0 & $\underline{8}$ & والإنتاجية \\
\hline $\mathbf{0}$ & 0 & 0 & 0 & 0 & 0 & 0 & 0 & 0 & 0 & $\underline{4}$ & والمسؤولية \\
\hline & 139 & 9 & 11 & 37 & 24 & 28 & 8 & 16 & 6 & $\underline{68}$ & المجموع الكلي \\
\hline & & 29.41 & & 89.70 & & 52.94 & & 32.35 & & & النسبة المئوية \\
\hline
\end{tabular}

الجدول (4) أن أعلى النسب التي تحققت للمؤشرات كانت في محور

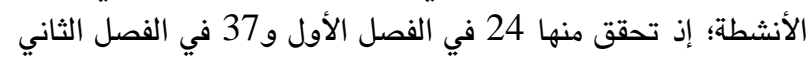

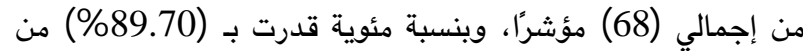

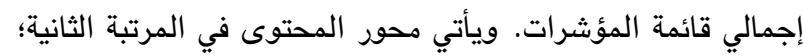
إن تحقق منها 8 في الفصل الأول و28 في الفصل الثاني بمان

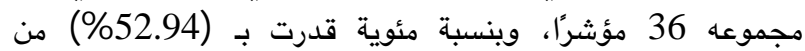
إجمالي قائمة المؤشرات. ويأتي محور الأهداف في المرتبة الثالثة؛
يتضح من الجدول (4) عدد المؤشرات المتحققة لكل مهارة

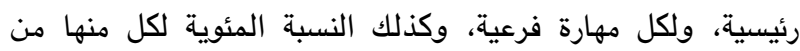

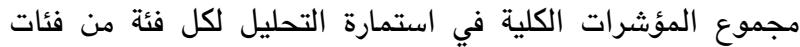

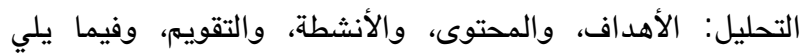
عرض لما تم التوصل إليه من نتائج: 1. هناك تفاوت في مدى تضمين مهارات القرن الحادي

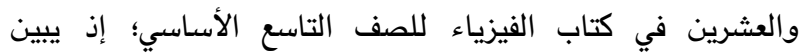


مع ظواهر طبيعية، مما يمكنهم من تفعيل التفكير الناقد وحل

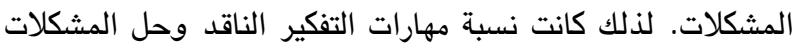

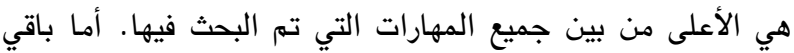
المهارات، فقد أظهرت النتائج تدني تضمينها في كتاب الفي تهي الفيزياء للصف التاسع الأساسي. وقد يعزى ذلك إلى غياب هذه المهارات عن أسس ومعايير

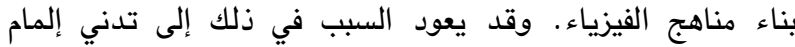
القائمين على إعداد المناهج بأهمية هذه المهارات في بناء شخصية الفياء

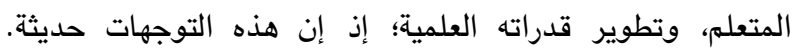

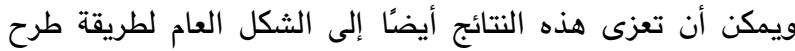

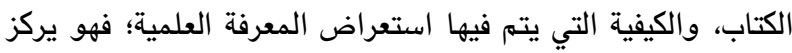

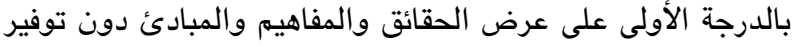

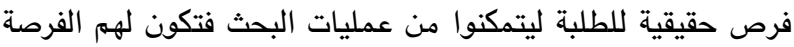

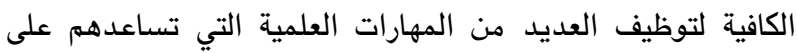

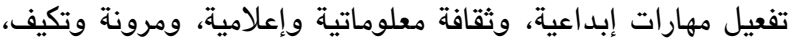

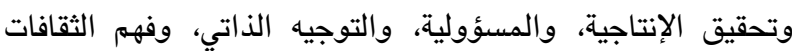

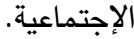

وتتفق هذه النتائج بجميع مهاراتها الرئيسية مع نتائج دراسة

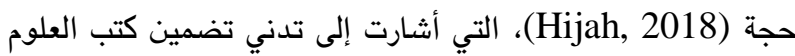

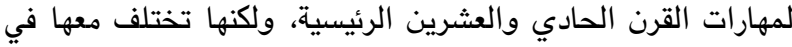

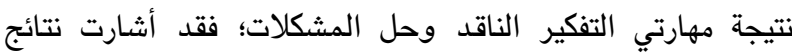

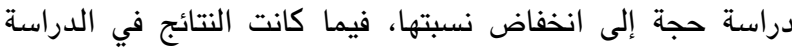

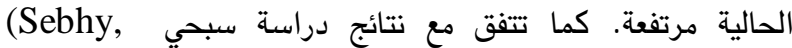
(2016 التي أظهرت نتائجها انخفاض مستوى نتائ دراسة تضمين مهارات القرن الحادي والعشرين في محتوى مناهج العلوم. وتختلف نتائج الدراسة الحالية مع نتائج دراسة المنصور (AlMansor, 2018) في مهارة التعلم والابتكار، التي حلت في المرتبة الأولى بدرجة

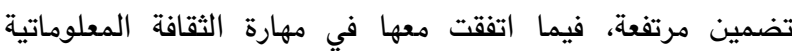
الرقمية التي احتلت درجة منخفضة. ب. نتائج التحليل المتعلقة بمهارات القرن الحادي والعشرين

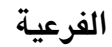

من خلال أداة الدراسة، تمت عملية تحليل محتوى كتاب

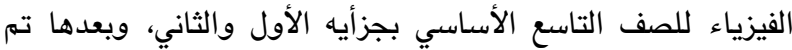
حساب عدد المؤشرات المتحققة لكل مهارة رئيسية في مجالات: الأهداف، والمحتوى، والانشطة، والتقويم، كما هو لهون موضح في في في مجالاتي

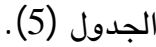

إذ تحقق منها 6 في الفصل الأول و16 في الفصل الثاني بما

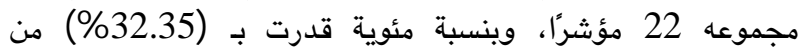
إجمالي قائمة المؤشرات. وأخيرًا جاء التقويم في المرتبة الأخيرة؛

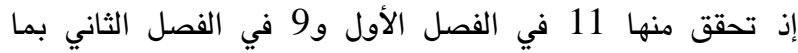

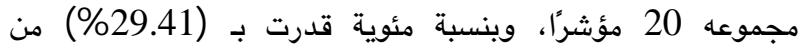
إجمالي قائمة المؤشرات.

ومن خلال استعراض النسب السابقة، نجد أن محور الأنثطة

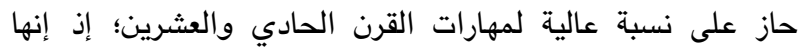

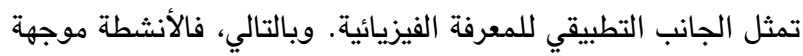

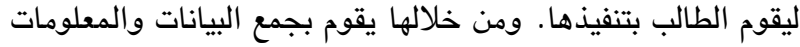

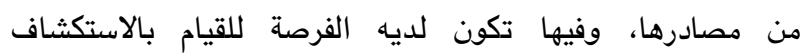

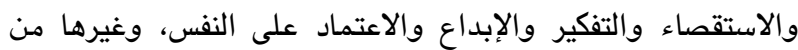

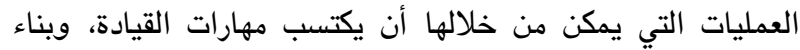

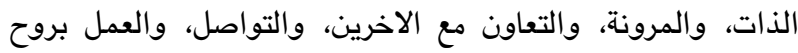

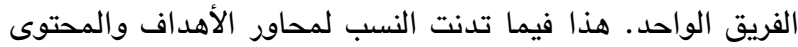

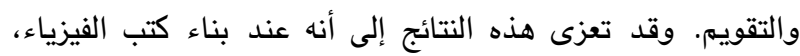

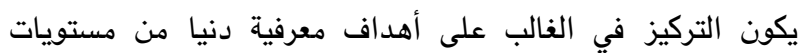

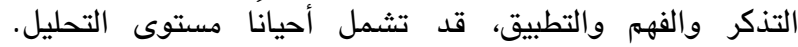

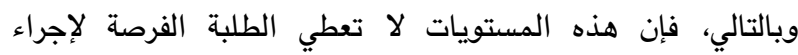

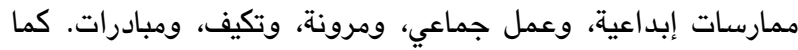
تخلو من القيادة والمسؤولية. 2. أظهرت نتائج الدراسة -على مستوى المهارات الرئيسية-

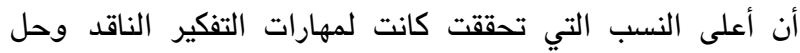

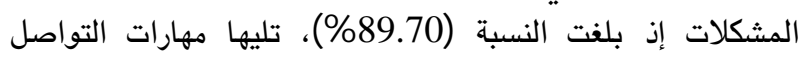

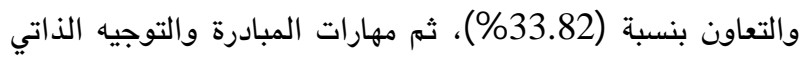

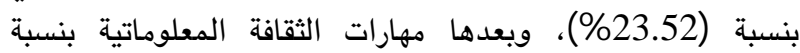

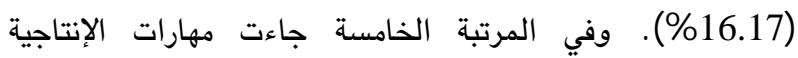

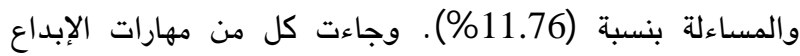

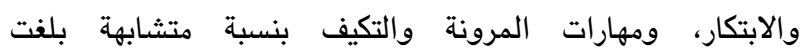

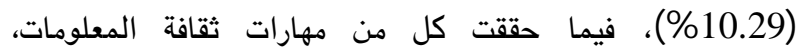
والاتصال، والمهارات الاجتماعية، وفهم الثقافات المتعددة ما نسبته

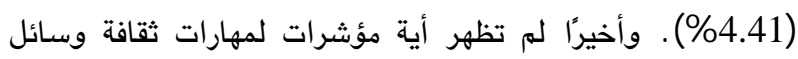
الإعلام، ومهارات القيادة، والمسؤولية؛ إذ بلغت النسبة (0.41\%). وتكثف النسب تفاوتًا واضحًا بين ما حققته مهارات التفكير

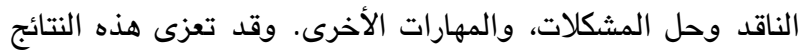

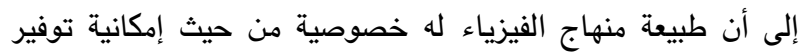

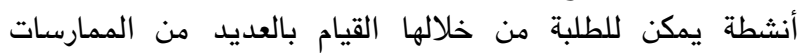
العملية، التي يمكن من خلالها مواجهته بمشكلات حياتية، والتعامل 
جدول (5): مواصفات كتاب الفيزياء للصف التاسع والنسب المئوية لمهارات القرن الحادي والعشرين الرئيسية والفرعية

\begin{tabular}{|c|c|c|c|c|c|c|c|c|c|c|c|}
\hline \multirow{5}{*}{ 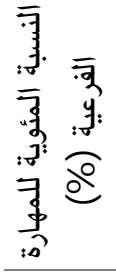 } & \multirow{5}{*}{$\begin{array}{l}\bar{z} \\
\vdots \\
\vdots\end{array}$} & \multicolumn{2}{|c|}{ التقويم } & \multicolumn{2}{|c|}{ الأنثطة } & \multicolumn{2}{|c|}{ المحتوى } & \multicolumn{2}{|c|}{ الأهداف } & \multirow{5}{*}{ المؤشرات - عدد } & \multirow{5}{*}{ المهارات الفرعية } \\
\hline & & الجزء & الجزء & الجزء & الجزء & الجزء & الجزء & الجزء & الجزء & & \\
\hline & & الثاني & الأول & الثاني & الأول & الثاني & الأول & الثاني & الأول & & \\
\hline & & المؤشرات & المؤشرات & المؤشرات & المؤشرات & المؤشرات & المؤشرات & المؤشرات & المؤشرات & & \\
\hline & & المتحققة & المتحققة & المتحققة & المتحققة & المتحققة & المتحققة & المتحققة & المتحققة & & \\
\hline 25.37 & 17 & 0 & 0 & 3 & 3 & 4 & 0 & 5 & 2 & 1 & التفكير بفاعلية \\
\hline 22.38 & 15 & 3 & 3 & 2 & 1 & 4 & 1 & 1 & 0 & 1 & استخدام التفكير \\
\hline 29.85 & 20 & 6 & 4 & 3 & 0 & 3 & 2 & 2 & 0 & 5 & واتخداذ القرارات الأحكام \\
\hline 13.43 & 9 & 0 & 2 & 2 & 0 & 1 & 2 & 2 & 0 & 2 & حل المشكلات \\
\hline 17.91 & 12 & 0 & 0 & 2 & 8 & 1 & 1 & 0 & 0 & 5 & التواصل بوضوح \\
\hline 16.41 & 11 & 0 & 0 & 2 & 9 & 0 & 0 & 0 & 0 & 4 & التعاون مع الآخرين \\
\hline 5.97 & 4 & 0 & 0 & 4 & 0 & 0 & 0 & 0 & 0 & 3 & التفكير بشكل خلاق \\
\hline 4.47 & 3 & 0 & 0 & 0 & 0 & 1 & 1 & 0 & 1 & 4 & العمل الابتكاري مع \\
\hline 0 & 0 & 0 & 0 & 0 & 0 & 0 & 0 & 0 & 0 & 1 & تنفيذ الابتكارات \\
\hline 8.95 & 6 & 0 & 0 & 4 & 0 & 2 & 0 & 0 & 0 & 2 & المعلومات وتقول إلىيمها \\
\hline 7.46 & 5 & 0 & 0 & 0 & 0 & 5 & 0 & 0 & 0 & 3 & 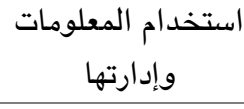 \\
\hline 0 & 0 & 0 & 0 & 0 & 0 & 0 & 0 & 0 & 0 & 3 & تحليل الإعلام \\
\hline 0 & 0 & 0 & 0 & 0 & 0 & 0 & 0 & 0 & 0 & 2 & ابتكار منتجات \\
\hline 4.47 & 3 & 0 & 0 & 0 & 0 & 1 & 0 & 0 & 2 & 3 & تطبيق التكنولوجيا \\
\hline 4.47 & 3 & 0 & 0 & 0 & 0 & 2 & 1 & 0 & 0 & 2 & التكيف مع التغيير \\
\hline 5.97 & 4 & 0 & 1 & 0 & 0 & 0 & 0 & 2 & 1 & 3 & المرونة \\
\hline 2.98 & 2 & 0 & 0 & 0 & 0 & 0 & 0 & 2 & 0 & 2 & إدارة الوقت \\
\hline 20.89 & 14 & 0 & 0 & 8 & 0 & 4 & 0 & 2 & 0 & 5 & العمل باستقلالية \\
\hline 1.49 & 1 & 0 & 0 & 0 & 1 & 0 & 0 & 0 & 0 & 2 & التفاعل بكفاءة مع \\
\hline 2.98 & 2 & 0 & 1 & 1 & 0 & 0 & 0 & 0 & 0 & 3 & فرق متنوعة بفاعلية في \\
\hline 0 & 0 & 0 & 0 & 0 & 0 & 0 & 0 & 0 & 0 & 2 & إدارة المشروعات \\
\hline 11.94 & 8 & 0 & 0 & 6 & 2 & 0 & 0 & 0 & 0 & 6 & الوصول إلى نتائج \\
\hline 0 & 0 & 0 & 0 & 0 & 0 & 0 & 0 & 0 & 0 & 3 & توجيه الآخرين \\
\hline 0 & 0 & 0 & 0 & 0 & 0 & 0 & 0 & 0 & 0 & 1 & المسؤولية عن \\
\hline
\end{tabular}


في ضوء نتائج الدراسة، توصي الباحثة بما يلي:

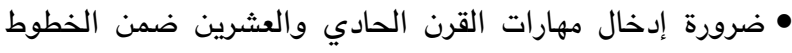

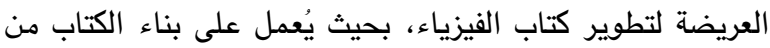
خلال تضمين هذه المهارات أجزاء الكتاب كافة.

• ضرورة تضمين المناهج مهارات تنمية جوانب الشخصية كافة،

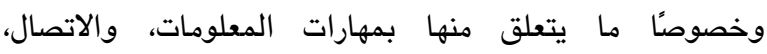
والمهارات الاجتماعية، وفهم الثقافات المتعددة، ومهارات المات ثقاتفات وسائل الإعلام، ومهارات القيادة، والمسؤولية.

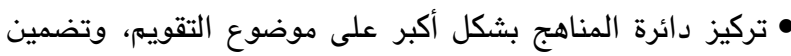
المناهج جوانب تقويمية تراعي مهارات القرن الحادي والعشئ العشرين

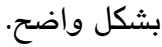
• إجراء المزيد من الدراسات التي تتعلق بمهارات القرن الحادي

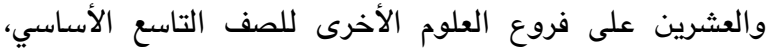
وكذلك على جميع فروع العلوم للصف العاشر للمرحلة الأساسية.
الفرعية، ويظهر تدن واضح لدرجة تضمينها في كتاب الفيزياء

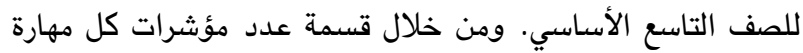

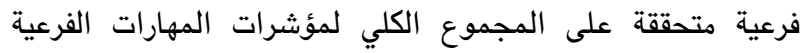

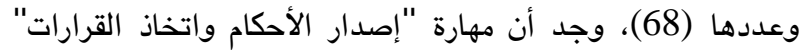

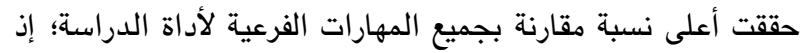

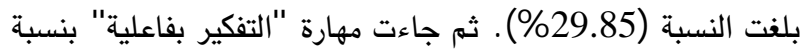

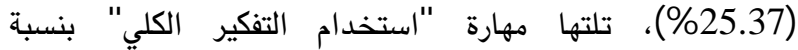

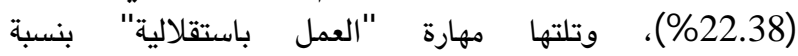

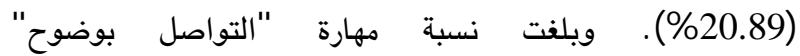

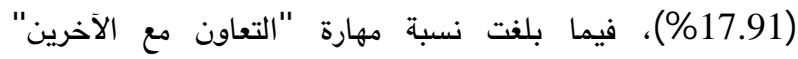

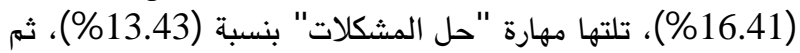

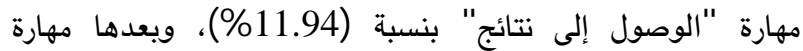

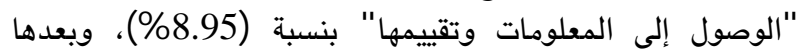

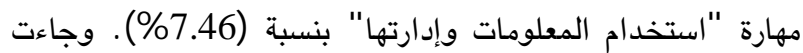
مهارة "التفكير بشكل خلاق"، ومهارة "المرونة" بنسبة (5.97\%)

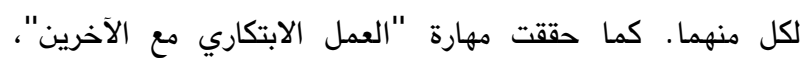

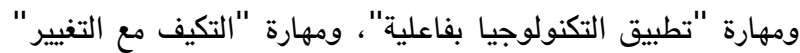

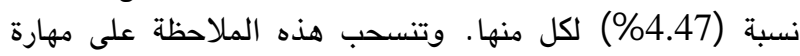

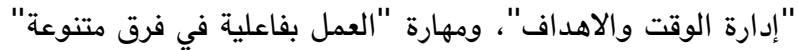

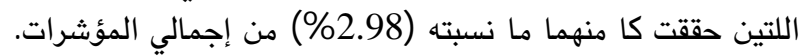

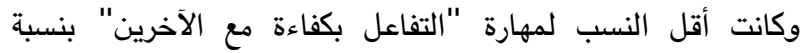

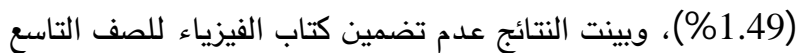

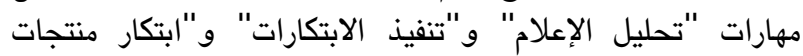

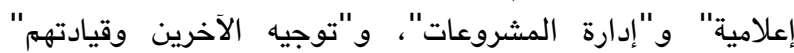

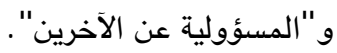

وتعزو الباحثة تدني مستوى تضمين المهارات الفرعية للقرن الحادي والعشرين في كتاب الفيزياء للصف التاسع الأساسي إلى أن الن تصني

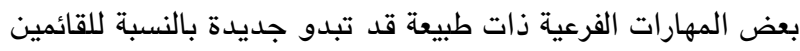
على تخطيط وتصميم المناهج، مقارنة بالمهارات التي اعتادوا عليها

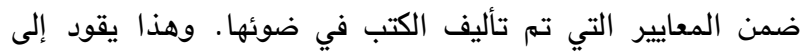
وجود صعوبات تحول دون إدراجها بوضوح في كتب الفيزياء، مثل:

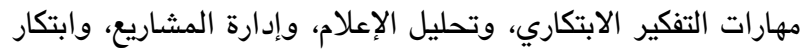

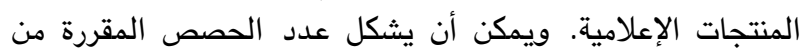

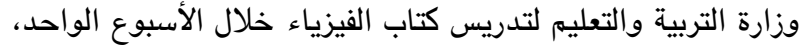

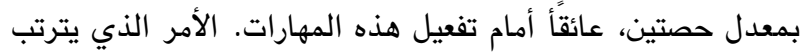

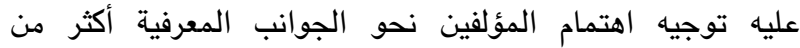
الجوانب المهارية. وتتفق نتائج الدراسة الحالية مع نتائج دراسة الباز

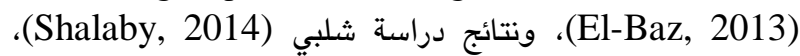
ونتائج دراسة حجة (Hijah, 2018)، التي أشارت جميعها إلى تدنٍ واضح في تناول مهارات القرن الحادي والعشرين في الكتب التي التي

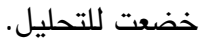




\section{References}

Al-Dahery, Y. (2002). Analysis of the content of physics books in the secondary stage in light of the entrance of science, technology and society. $\mathrm{PhD}$ Dissertation, Um Al-Qura University, Saudi Arabia.

AlMansor, A. (2018). Inclusion of $21^{\text {st }}$ century skills in the content of science textbooks at the basic education stage in Jordan. $\mathrm{PhD}$. Dissertation, Aal-Al Bayt University, Jordan.

Al-Qadri, S. (2005). Obstacles to learning physical concepts from the viewpoint of physical teachers in northern Jordan. Al-Manara, 10 (4), 101-126.

Al-Sheikh Eid, J. (2009). Physical dimensions of literacy included in the platform for the content of physics for the eleventh-grade students and their acquisition of it. Master Thesis, Islamic University in Gaza, Gaza.

Al-Tweissat, N. (2011). Analytical study of secondary stage physics textbooks' content in light of the scientific literacy requirements. Master Thesis, Yarmouk University, Jordan.

Al-Yousef, I. (2018). An analytical study of the content of textbooks developed for secondary school in light of STEM-oriented criteria. Master Thesis, Yarmouk University, Jordan.

Binkley, M., Erstad, O., Herman, J., Raizen, S., Ripley, M., Miller-Ricci, M. et al. (2012). Defining twenty-first century skills. In P. Griffin, B. McGaw \& E. Care (Eds.), Assessment and teaching of $21^{\text {st }}$ century skills: Methods and approach (pp. 17-66). Dordrecht: Springer.

Burkhardt, G., Monsour, M., Valdez, G., Gunn, C., Dawson, M., Lemke, C. Coughlin, E., Thadani, V. \& Martin, C. (2003). $21^{\text {st }}$ century skills: Literacy in the digital age. https:// pict.sdsu.edu/engauge21st.pdf.

Chalkiadaki, A. (2018). A systematic literature review of $21^{\text {st }}$ century skills and competencies in primary education. International Journal of Instruction, 11(3), 1-16.

Educational Testing Service (ETS). (2007). Digital transformation: A literacy framework for ICT literacy. https://www.ets.org/Media/ Research/ pdf/ICTREPORT.pdf.
El-Baz, M. (2013). Developing the science curriculum for the third preparatory grade in light of the skills of the $21^{\text {st }}$ century. Journal of Scientific Education, 16(6), 1-42. Retrieved on 7 January 2019 from the website: https://portal. arid.my/Publications/f0b6ddd7b75b-48.pdf.

Ferrari, A. (2012). Digital competence in practice: An analysis of frameworks. Seville: Joint Research Centre, Institute for Prospective Technological Studies. http://dx.doi.org/ 10. 2791/82116.

Greenhill, V. (2010). $21^{\text {st }}$ century knowledge and skills in educator preparation. partnership for century skills. https://eric.ed.gov/?id $=\mathrm{ED} 519336.2 / 2 / 2018$.

Hammad, I. (2013). The degree of relevance of the physics textbooks for the ninth and tenth grades of basic learning outcomes from the point of view of physics teachers in Zarqa governorate. Master Thesis, University of Jordan, Jordan.

Hammoudeh, M. (2009). Analysis of Jordan's science textbooks: A socio-linguistic perspective. Master Thesis, Hashemite University, Jordan.

Hassania, G. (2013). Assessment of the $9^{\text {th }}$ grade physics textbook in Jordan including the content standard of the National Science Education Standards (NSES). Al-Manara Research and Studies - Social Sciences, 19(3), 173-211.

Hijah, H. (2018). The extent to which science textbooks fpr the upper basic stage include the $21^{\text {st }}$ century skills. Dirasat, 45(3). 163-178.

Hiong, L. \& Osman, K. (2013). A conceptual framework for the integration of 21 st century skills in biology education. Research Journal of Applied Sciences, Engineering and Technology, 6(16), 2976-2983; DOI:10.19026/ rjaset.6.3681.

Laar, E., Deursen, A., Dijk, J. \& Haan, J. (2017). The relation between $21^{\text {st }}$ century skills and digital skills: A systematic literature review. Computers in Human Behavior, 72, 577-588. 
Leahy, D. \& Dolan, D. (2010). Digital literacy: A vital competence for 2010 in key competencies in the knowledge society (pp. 210-221). Berlin -Heidelberg: Springer.

Ministry of Education. (2017). The general framework for research, evaluation and the general and special results of all academic textbooks. Retrieved on August 17, 2019, from: http://www.moe.gov.jo/SectionDetails. aspx? SectionDetailsID=226.

National Science Teachers Association (NSTA). (2011). " Quality science education and 21stcentury skills". http://science.nsta.org.

Nofal, D. (2017). The degree of $21^{\text {st }}$ century science practices in $8^{\text {th }}$ grade science book in Jordan. Master Thesis, Hashemite University, Jordan.

Partnership for $21^{\text {st }}$ Century Skills. (2009a). Curriculum and instruction: A $21^{\text {st }}$ century skills implementation guide. http://www.p21. org.

Partnership for $21^{\text {st }}$ Century Skills (2009b). Professional development: A $21^{\text {st }}$ century skills implementation guide. http://www.p21. org.

Partnership for $21^{\text {st }}$ Century Skills. (2008). $21^{s t}$ century skills, education and competitiveness: A resource and policy guide. Washington: Author.
Raphael, E. \& Youssef, M. (2001). Teaching and learning mathematics in the $21^{\text {st }}$ century. Cairo: Anglo Egyptian Library.

Sebhy, N. (2016). The extent to which the skills of the $21^{\text {st }}$ century are included in the science curriculum developed for the first intermediate grade in Saudi Arabia. Journal of Educational Sciences, 1(1), 9 -50.

Shalaby, N. (2014). A proposed framework for integrating $21^{\text {st }}$ century skills in science curricula with basic education in Egypt. International Journal of Educational Specialization, 10(3), 2-30.

Trilling, B. \& Fadel, C. (2009). $21^{\text {st }}$ century skills: Learning for life in our times. San Francisco, Jossey-Bass.

Trilling, B. \& Fadel, C. (2013). $21^{\text {st }}$ century skills: Learning for life in our times. Riyadh: King Saud University.

Wang, W. (2011). A Content analysis of reliability in advertising content analysis. Retrieved from: http://dc.etsu.edu/etd/1375.

Zaanin, J. \& Shabat, M. (2002). Development of physics curricula in secondary schools in Palestine for the $21^{\text {st }}$ century. Journal of the Islamic University of Natural Studies, 10(1), 33-43. 